Florida International University

FIU Digital Commons

FIU Electronic Theses and Dissertations

University Graduate School

$4-2-2004$

\title{
Information model for engineering change management
}

Clifford L. Panokarren

Florida International University

Follow this and additional works at: https://digitalcommons.fiu.edu/etd

Part of the Industrial Engineering Commons, and the Systems Engineering Commons

\section{Recommended Citation}

Panokarren, Clifford L., "Information model for engineering change management" (2004). FIU Electronic Theses and Dissertations. 3949.

https://digitalcommons.fiu.edu/etd/3949

This work is brought to you for free and open access by the University Graduate School at FIU Digital Commons. It has been accepted for inclusion in FIU Electronic Theses and Dissertations by an authorized administrator of FIU Digital Commons. For more information, please contact dcc@fiu.edu. 
FLORIDA INTERNATIONAL UNIVERSITY

Miami, Florida

INFORMATION MODEL FOR ENGINEERING CHANGE MANAGEMENT

A thesis submitted in partial fulfillment of the

requirements for the degree of

MASTER OF SCIENCE

in

INDUSTRIAL AND SYSTEMS ENGINEERING

by

Clifford L. Panokarren

2004 
To: Dean Vish Prasad

College of Engineering

This thesis, written by Clifford L. Panokarren, and entitled Information Model for Engineering Change Management, having been approved in respect to style and intellectual content, is referred to you for judgment.

We have read this thesis and recommend that it be approved.

Shih-Ming Lee

Joe Chow

Chin-Sheng Chen, Mdjor Professor

Date of Defense: April 2, 2004

The thesis of Clifford L. Panokarren is approved.

Dean Vish Prasad eorlege of Engineering

Dean Dougas Wartzok University Graduate School

Florida International University, 2004 


\section{DEDICATION}

This thesis is dedicated to my parents, my sister and her two wonderful kids and to my committee members Dr. Chen, Dr. Lee and Dr. Chow. Without their patience, continuous and timely support, the completion of this work would not have been possible. This may be an appropriate tribute to all of them. 


\section{ACKNOWLEDGMENTS}

I wish to express my most sincere gratitude to Dr. Chin-Sheng Chen for his unparalleled and exemplary guidance to me in completion of this research and under whom conducting research has always been a challenging and interesting task. He has been instrumental in guiding me with the qualitative concept of this work. Every moment of work done under his guidance has been a learning experience for me. I also would like to extend my sincere thanks to Dr. Lee and Dr. Joe Chow for serving on my committee and guiding me when the need aroused.

My sincere thanks also to Mr. Mario Sanchez, who helped me out to plot the oversize materials of this research and for taking out time from his busy schedule and advice me on important issues of this research. A special thanks to my friend Ms. Mansi Shrivastava who helped me put together the final version of my thesis report. Last but not the least, special thanks to Ms. Nancy Urbina the secretary of the department of Industrial \& systems engineering for helping me out in administrative matters. 


\begin{abstract}
OF THE THESIS
INFORMATION MODEL FOR ENGINEERING CHANGE MANAGEMENT

by

Clifford L. Panokarren

Florida International University, 2004

Miami, Florida

Professor Chin-Sheng Chen, Major Professor

Managing engineering changes is a critical task for organizations to remain competitive. In a manufacturing organization there are innumerable engineering change requests. This thesis is focused on the development of an information model that defines
\end{abstract} the engineering change process.

This research developed an activity model in IDEF0, an object model in IDEF1X and a dynamic model using state diagrams. The activity model captures the business process for executing an engineering change in terms of its constituting activities and sub-activities. The object model defines each object and its attributes identified in the activity model. The dynamic model captures the status change of each object in the engineering change process. This study concludes with a summary, implementation issues and future work that can be done in the direction of implementing a system based on the information model developed. 


\section{TABLE OF CONTENTS}

CHAPTER

PAGE

I INTRODUCTION

1

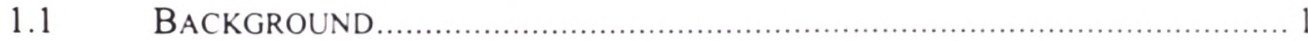

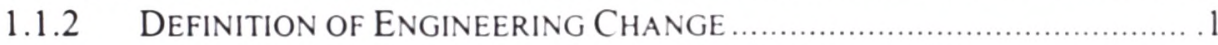

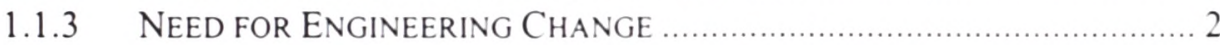

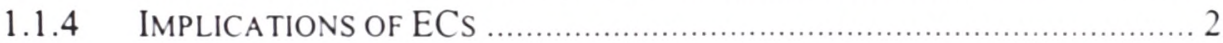

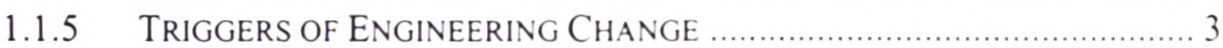

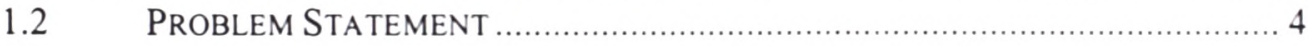

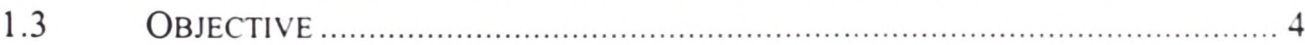

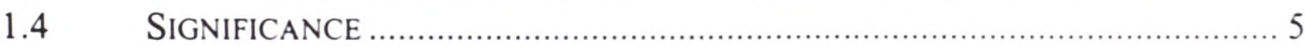

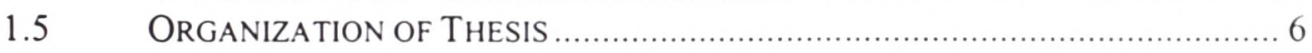

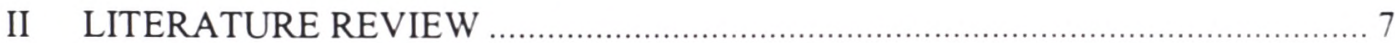

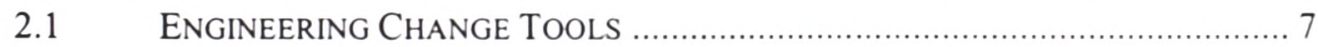

2.2 BLOCK FREEZE MECHANISM …......................................................... 8

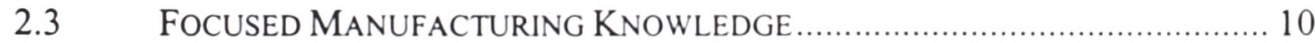

2.4 EC FROM THE BPR PERSPECTIVE....................................................... 10

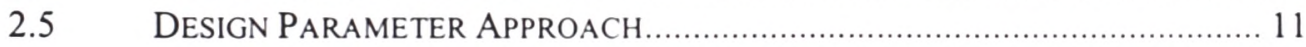

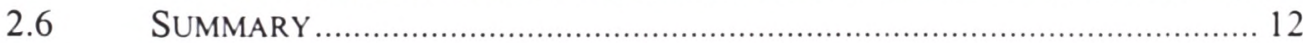

III THE ENGINEERING CHANGE INFORMATION MODEL ......................... 14

3.1 The Product development Process ........................................... 14

3.2 The ENGINEERING Change Process.................................................. 16

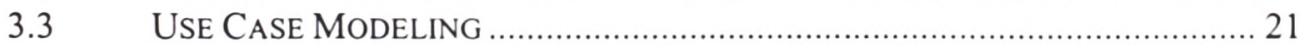

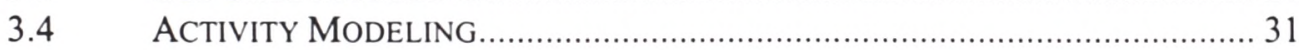

OBJECT MODELING .............................................................................. 41

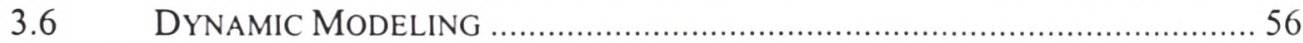

3.6.1 FRAMEWORK FOR THE DYNAMIC MODEL ................................... 56

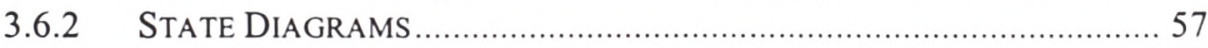

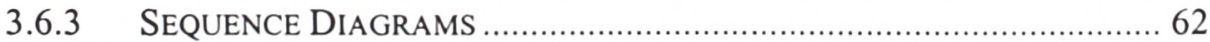

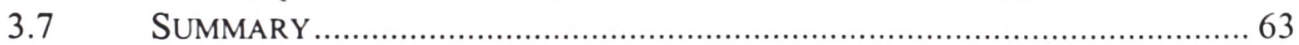

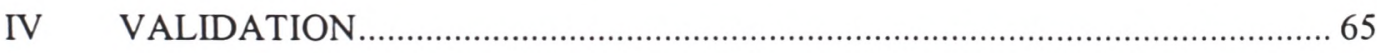

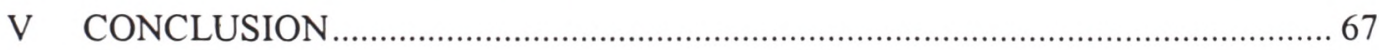

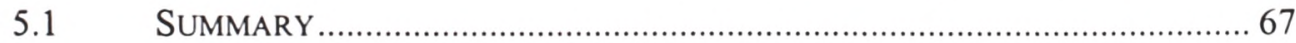

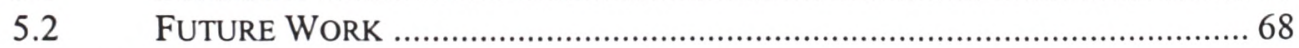

5.2.1 REFINEMENT OF THE INFORMATION MODEL ...................................6 68

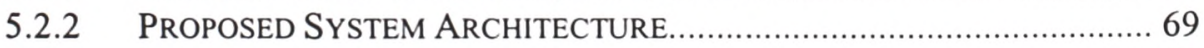

$5.2 .3 \quad$ IMPLEMENTATION ISSUES ................................................... 72

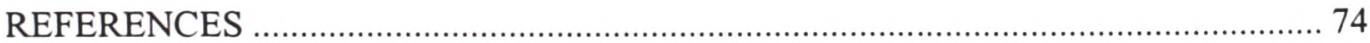

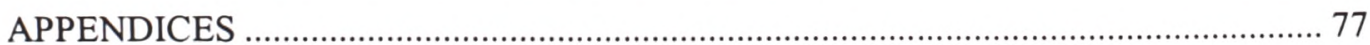




\section{LIST OF TABLES}

TABLE

Table 1: Use case for 'Request an $\mathrm{EC}^{\prime}$ 22

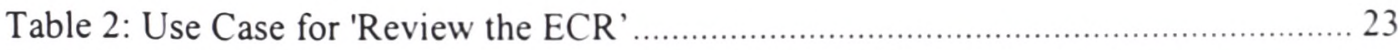

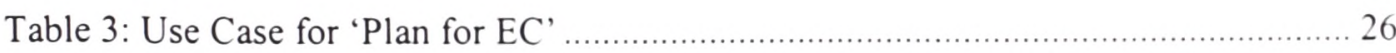

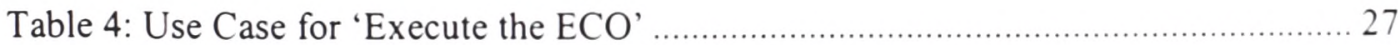

Table 5: Use Case of 'Post Implementation Assessment'/ECN' .................................. 29

Table 6: Complete object list from Activity Model ................................................... 42

Table 7: List of objects for the activity 'Request an EC' ............................................. 42

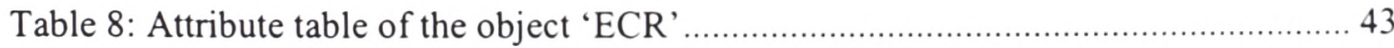

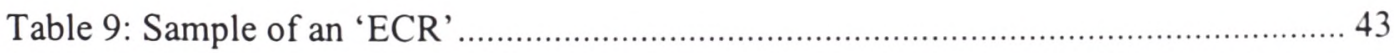

Table 10: Attribute table of the object 'EC board/committee' ....................................... 44

Table 11: Attribute table of the object 'EC board/committee leader' .............................. 44

Table 12: Attribute table of the object 'Functional Department' .................................... 44

Table 13: Attribute Table of the object 'Functional Department' .................................... 45

Table 14: List of Objects of 'Review an EC' Use Case ................................................ 45

Table 15: Attribute table of the object 'EC Review' ......................................................... 45

Table 16: Attribute table of the object 'EC Quote'........................................................... 47

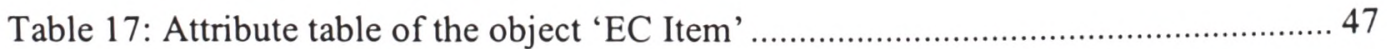

Table 18: Attribute table of the object 'EC Review Report' ............................................ 47

Table 19: List of objects of 'Order an EC' Use Case ........................................................ 49

Table 20: Attribute table of the object 'ECO' ..................................................................... 49

Table 21: Attribute table of the object 'Product Item' .................................................... 50 
Table 22: List of objects of 'Deploy an ECO' Use Case.

Table 23: Attribute table of the object 'ECN' ......................................................... 52

Table 24: List of objects of 'Conduct Post-Implementation Assessment' Use Case ....... 54

Table 25: Symbols and Cardinalities for 'Object class model for ECM' ........................ 54 


\section{LIST OF FIGURES}

FIGURE

PAGE

Figure 1: Various ECs relative to the Product Design Stages 16

Figure 2: Collaborative EC process 18

Figure 3: Activities in Engineering Change Management.

Figure 4: Overview of the Development of the Information Model 20

Figure 5: Use Case diagram of 'Review an EC' 25

Figure 6: Use Case diagram for 'Create an ECO' 26

Figure 7: Use Case diagram of 'Execute the EC' 28

Figure 8: Use Case diagram of 'Post-Implementation Assessment/ECN' 30

Figure 9: IDEF0 diagram of 'Managing an Engineering Change' 31

Figure 10: Hierarchical diagram of activities to mange ECs 32

Figure 11: The IDEF0 Activity Model for 'Managing Engineering Changes' 34

Figure 12: The decomposed IDEF0 Model of 'Review an Engineering Change'............ 36

Figure 13: The IDEF0 Model of 'Execute an EC' 37

Figure 14: The IDEF0 Functional Model of 'Post-Implementation Assessment' 38

Figure 15: The IDEF0 Functional Model for decomposition of 'Implement ECO' 40

Figure 16: Object Class diagram of 'Request an EC' Use Case 46

Figure 17: Object Class diagram of 'Review an EC' Use Case 48

Figure 18: Object Class diagram of 'Plan for EC/Create an ECO' Use case 51

Figure 19: Object Class diagram of 'Execute the EC' Use case 53

Figure 20: Object Class diagram of 'ECN' 55

Figure 21: Object life cycle of 'ECR' 58 



\title{
LIST OF ACRONYMS
}

\author{
$\mathrm{EC}=$ Engineering Change. \\ ECRs $=$ Engineering Change Requests. \\ $\mathrm{ECM}=$ Engineering Change Management. \\ $\mathrm{ECN}=$ Engineering Change Notification. \\ ECMS $=$ Engineering Change Management System. \\ PD $=$ Product Development \\ EDMS $=$ Engineering Data Management System. \\ $\mathrm{ECO}=$ Engineering Change Order. \\ $\mathrm{CAD}=$ Computer-aided-design. \\ CAECC $=$ Computer-aided-Engineering-Change-Control . \\ $\mathrm{OEM}=$ Original Equipment Manufacturer. \\ ROI $=$ Return on Investment. \\ $\mathrm{PDM}=$ Product Data Management. \\ $\mathrm{BOM}=$ Bill of Materials. \\ $\mathrm{MRP}=$ Materials Resource Planning
}




\section{CHAPTER \\ I INTRODUCTION}

\subsection{BACKGROUND}

In order to be successful and competitive, companies not only have to entertain engineering change requests (ECRs) but also manage it efficiently. There is a belief that product design is more of inspiration than perspiration. But this rationale depends on the product type designed and the stage the design process has reached. In a manufacturing organization there are innumerable numbers of ECRs. These arise from various sources right from the ones initiated by the customers' change in specifications to the ones arising from a product design being unsafe.

\subsubsection{Definition of Engineering Change}

Huang et al (1999) define engineering changes as changes and modifications on forms, fits, materials, dimensions, functions and processes for the manufacture of a product or component. Chen et al (2002) define engineering change (EC) as a task by which companies request, implement and affect changes to products, documents, processes or even raw-materials. Wright (1997) defines ECs as modifications to a product, after the raw-materials have entered production. ECs can be as simple as changes in documentation related to the design of a product or they may be as complicated as an entire redesign of the entire product and its related manufacturing processes. Dec et al (1998) state that 'engineering change is a task by which companies request, implement and affect changes to products, documents, components, manufactured or purchased parts, processes or even supplies.' ECs have serious implications in any company because it could involve all the functions across the entire 
organization. Various functional departments of an organization may not only be the source but also the victims of an EC. Manufacturing companies have to constantly cater to ECs and constantly adjust their activities.

\subsubsection{Need for Engineering Change}

Competition in the market demands that companies develop and manufacture complex products with higher quality and lower price to stay competitive. The product life cycles have decreased significantly, which underline the importance to develop the products in a shorter time in order to maximize the market. The old sequential way of performing product development (PD) and produce large series of products is turning into production of customer variants with a fast adaptation to changing customer needs. This requires that the EC process be performed quickly. An increasing product complexity utilizing multiple technologies along with a shorter time for the PD makes it necessary to have more people with different competencies involved in each PD project. However, changes due to wrong decisions and changes in customers' requirements are unavoidable. The impact of any ECR has to be investigated. This also involves fluent flow of information related to the product and process items within all the affected departments.

\subsubsection{Implications of ECs}

Effective control over the management of engineering changes will facilitate proper execution of ECs especially in the terms of lead-time and costs incurred, thereby increasing profitability. Balcerak and Dale (1992) point out that inefficient control over ECs may result in adverse impacts which include effects on delivery time, production schedules, scrap, rework and low BOM accuracy. Huang and Mak (1996) have reported administrative costs pertaining to engineering changes to the tune of US \$ 3.4-7.7 million 
and execution costs to $10 \%$ of annual turnover. Engineering changes occurring frequently determine $70-80 \%$ of the product cost (McIntosh, 1995).

\subsubsection{Triggers of Engineering Change}

Organizational, technological and operational changes are often causes for engineering changes (Huang and Mak, 1997). There are various kinds of ECRs that arise in an organization. ECRs may appear at various stages of the PD process. The possible causes of these ECRs are identified below:

$>$ ECRs arising due to changes in customer specifications.

$>$ ECRs arising due to faults in the transformation of customer needs into technical requirements.

$>$ ECRs due to changes in customer needs.

ECRs due to changes in architectural design.

$>$ ECRs due to changes in component design.

ECRs due to changes in process design.

ECRs due to change in use of resources.

ECRs arising due to difficulties in parts fabrication or assembly.

ECRs can also originate from different causes apart from the ones mentioned above. For example:-

$>$ Change of a part depending on altered function or production requirement.

$>$ Change in application of a part/component/subcomponent.

$>$ Introduction / replacement/ withdrawal of a new part/component/ subcomponent. 


\subsection{Problem Statement}

Management of engineering changes depends on the engineering process as well as management of information pertaining to the engineering process (Chen et al, 2002). There is a need for a structured and generic model to store, integrate, manage and control both the EC data and the EC process. Thus the problem statement can be stated as:-Lack of an information model to guide the EC process.

\subsection{OBJECTIVE}

The prime objective of this research is to capture the EC process flow and data to guide the execution of engineering changes. Thus the information model should be able to facilitate the orderly and effective management of the EC process and the EC data. This objective is based on a set of criteria as stated below:-

The information model must have a process model which handles various types of ECRs arising in a manufacturing setting. The PD process has various stages. An ECR can arise at any of these PD stages. For example, when a product is in the fabrication stage, the customer can always come back and request for changes in product specifications. Therefore the criterion of the model is that it should be able to handle any type of ECR at any PD stage.

Managing engineering changes is a business process (Chen et al, 2002). A business process is composed of constituting activities that have to be executed. Capturing a business process in its logical activities greatly simplifies the execution of the business process. Thus the other criterion of developing this model is to capture the 
business process of managing engineering changes in its constituting activities. This paves the way to develop a generic EC model.

The EC process model must align itself with the concepts of process integration and information integration (information related to engineering changes). This can be achieved by the development of a detailed activity model which will streamline the essential functions and sub-functions necessary to plan and implement an EC.

The information model must consider reports and notifications generation like ECR, EC review reports and ECNs. It must capture all data entities (objects) in the EC process, their life cycle and define them in terms of their attributes so that tracking of these entities becomes easier for the participants of the EC process. It must align the EC process to the PD process so that the participants in the EC process get the flexibility to request an $\mathrm{EC}$ at any stage in the $\mathrm{PD}$ process.

\subsection{Significance}

The significance of the information model can be discussed in terms of its possible uses. Since the information model (activity model) captures the business process of EC in terms of its constituting activities, it can be used to establish and identify the roles and responsibilities of all functional participants in the EC process. This information model can be used by manufacturing organizations as a blueprint to develop an ECM information system. In case of organizations that do not have the ability to develop an ECM information system this model can be used as a standard operating procedure for their EC process. The objects and their attributes from the object model can be used to define the forms like ECR, ECN and ECO. The dynamic model has captured 
the life cycle of critical objects (ECO, ECR and ECN) in the EC process. This will help to track the status of these objects in the EC process.

\subsection{ORganization OF Thesis}

The thesis is organized in 5 chapters. Chapter 2 reviews the literature in the field of ECM. Chapter 3 covers the development of the EC model starting with use case modeling to develop the activity model. After the development of the activity model, object modeling (IDEF1X) is done wherein all the objects of the EC process are identified and defined in terms of their attributes using object class diagrams and attribute tables. The dynamic model captures the dynamics of critical objects, their life-cycle and the state change in critical objects due to trigger of an EC event. Sequence diagrams in Appendix A show the interaction between objects of the EC process and the events that trigger the state change. Chapter 4 talks about the validation of the information model which argues as to how the objectives of the research were met. Chapter 5 summarizes this study and discusses the future work 


\section{CHAPTER}

\section{LITERATURE REVIEW}

The research into ECM can be divided into management concepts of engineering changes and existence of some industry specific tools. The literature review will give a brief overview of some suggested frameworks and methodologies for managing engineering changes. The following section cites some EC tools which are industry specific. Suggested methodologies and frameworks are discussed along with their inadequacies to manage engineering changes.

\subsection{Engineering Change ToOls}

EC tools are specific to particular industries and products since every product has its own product architecture. One of the major problems frequently associated with EC, is to ensure that only current documentation is available to manufacturing areas. Lack of adequate control over documentation can mean that components and assemblies are manufactured to instructions that have become outdated due to a subsequent EC. It is frequently argued that any appropriate computer-aided design (CAD) tool is capable of decreasing the number of engineering changes by giving the engineer increased opportunity for simulation and iteration prior to the launch of a new product or the modification of an existing one. Hays and Sun (1995) on this basis argue that all CAD packages have an effect of reducing the number of engineering changes but not eliminating them.

Huang and Mak (1997) talk about Computer Aided Engineering Change Control (CAECC) systems that create 'electronic forms' equivalent to the traditional ECRs and ECNs. Users with varying roles can use these facilities to capture, retrieve and process 
EC data. Kidd and Thomson (2000) cite in-house computer tools made by companies for their own manufacturing operations. The most appropriate example cited by them is of the British Aerospace (BAE) - Military Aircraft Division (MAD). This computer aid has the functionalities of initiating a design change proposal and assessing the viability of a design change. Maull et al (1992) have suggested an ECM process in order to help companies understand what an EC is, its implications on other systems, its costs and how the process of managing the EC can be improved.

Drawbacks of the process: -

This process can act only as an overall framework and is more inclined to new product development rather than executing an EC.

$>$ This process cannot guide the evaluation of an EC in terms of cost and leadtime. Functional participants do not include other important participants like quality control, purchasing and finance, which might have a role to play in the execution of an EC.

The information model developed as part of this research addresses the above mentioned drawbacks, since it is an EC process model developed from the very basic PD process. Review of engineering changes, which is a part of this model, also addresses the issue of analyzing the impacts on cost and lead-time.

\subsection{BLOCK FreEZe MechanisM}

Huge (1997) suggests the 'Block Freeze Mechanism' for executing engineering changes which is been practiced by many general-purpose computers manufacturers. This methodology is critiqued in this research because it just provides an overall procedural approach rather than an activity-based approach. It consists of the following phases: - 
Phase I (0-3 months): This is the period after the release of the initial design drawings to when the first unit is shipped to the customer. Approximately $70 \%$ of the changes occur during this period, which represents $10 \%$ of the product life cycle. The author talks about an approach called the 'Block Freeze' approach i.e. changes will be implemented at certain points in time. All the change requests are collected and categorized over this period of time and the period is called the 'Freeze' period. The categorization will depend on the type of the change request. In this case the author has categorized the changes into mechanical, logic, hardware and documentation. This mechanism implements groups of similar changes at one time rather than executing each change one at a time as they are released.

Phase II: This is the phase from 3 to 18 months after the first customer shipment. The design is basically stabilized by this time and the volume of changes is comparatively lesser than the phase I. A Return on Investment (ROI) analysis is performed on all the change requests at this point of time and all the steps after the ROI analysis are the same as in phase I.

Phase III: This period begins after the design has been frozen (approximately 1824 months) and extends through the rest of the product life cycle. Example: - a new law requiring a safety device or perhaps prolonged field experience would reveal a cost effective reliability improvement. 


\section{Disadvantages of the Block-Freeze Mechanism:-}

$>$ Changes are collected over a period of time, which is called the 'Block Freeze Period' which will not help execution of changes as a result of contractual obligations.

$>$ This mechanism does not identify the roles of functional participants.

$>$ Like other mentioned mechanisms it does not take into consideration any change request initiated due to change in customer requirements.

$>$ Changes that can occur at the various stages of the PD process are neglected.

\subsection{Focused Manufacturing KNOWLedge}

Baruch et al (1993) advocate 'Focused Manufacturing Knowledge' wherein they give an exploratory analysis of how PD engineers can avoid manufacturing-related engineering changes if they develop 'Focused Manufacturing Knowledge'. A design engineer can achieve this by working in an existing area of manufacturing, most related to that engineer's development task. The authors mention analyzing the impacts but do not substantiate the analysis of the impacts in terms of cost, lead time or quality. They recommend implementing change in the prototype before analyzing the impacts of the change. Again the EC process is initiated without evaluating the change request, which happens to be a fundamental drawback of the whole framework.

\subsection{EC FROM THE BPR PERSPECTIVE}

Huang et al (1998) have proposed to apply 'Business Process Re-engineering' (BPR) concept to rationalize the ECM process. They have proposed the incorporation of an ECM procedure as a single step in a BPR framework. The authors recommend this procedure for a company, which does not have an ECM system in place. They further 
substantiate that this framework can be used also by those companies that already have an existing ECM system in place. This framework, which comes nearest to recommending an approach, mentions about evaluating an EC in terms of its impacts. Although it does not mention about analyzing the impacts in terms of parameters it is highly imperative that the impacts can be measured in terms of lead-time and costs.

Although this perspective does not fulfill an efficient EC criterion, it assumes that all changes can be executed in the same manner irrespective of its type. It mentions the characterization of changes into its types as a step after analyzing the impacts. It mentions analyzing the impacts, but like all the above-mentioned frameworks, it does not mention the metrics by which an EC can be evaluated. It does not mention the functional participants and the roles that might be played by them, and it also applies an analogy of BPR to execution of engineering changes.

\subsection{Design Parameter Approach}

Rouibah and Caskey (2003) have proposed a design oriented approach to engineering changes called 'Design Parameter' approach. They define 'Design Parameters' as basic engineering attributes for which engineering changes have to be implemented. It can be weight, space (length/distance), force, speed, movements and dimension with magnitude and/or direction. They can also be defined as engineering attributes which will have engineering values or whose values have to be changed because of an ECR. Parameters refer to decisions that need to be taken in order to implement an ECR. Design parameters are linked to each other, as are components/sub components for a particular product. Capturing the relationships between them clearly will capture the relation between those functional entities/disciplines (design, 
manufacturing, quality, etc) that handle these design parameters. Thus design parameters link processes, people and product items (components/sub components). The capture of the inter-relationships between these design parameters can be used to support an intelligent EC process. Rouibah and Caskey (2003) also mention other interdependencies as follows:-

$>$ Interdependent design parameters.

$>$ Design parameters and component/ subcomponent interdependencies.

$>$ Product component/ subcomponent and manufacturing processes interdependencies (product-process) interdependence.

$>$ Product component/ subcomponent and other component/ subcomponent within the same subsystem interdependence (intra-unit product-component coupling).

$>$ Interdependence between product component/ subcomponent and other component/ subcomponent in different subsystems.

\subsection{SUMMARY}

By far most of the EC studies suggest methodologies which are more inclined toward the administrative issues for ECM. They suggest the basic elements for an EC procedure. There is a void in the approaches toward EC and that is, 'considering EC process as predominantly a process of correcting mistakes rather than a process which should be more aligned toward PD'. Thus engineering changes can also be seen as a way for incremental PD. There are customized tools developed by manufacturing organizations tailored to industry needs. No work has been done which will capture the 
EC process flow and the EC data. This research will focus on developing a generic model for all types of engineering changes. 


\section{CHAPTER}

\section{THE ENGINEERING CHANGE INFORMATION MODEL}

This chapter concentrates on the logical development of the EC information model. Management of the EC process and EC information should happen in an integrated fashion both within the enterprise and outside the enterprise amongst its allied partners. Various metrics (reviewed in chapter2) are used to measure the efficiency of an EC process, some of which are time and cost. Time can be measured in terms of amount of time for requesting an EC, reviewing an ECR, implementing an ECR, amount of unscheduled time for processing an ECR. Cost can be the net cost for making an EC, administration cost of an EC, cost of rework and scrap for an EC and also un-estimated cost for processing an EC and the final costs for implementing those changes.

The following section will discuss the PD process and the possible types of changes that can occur at any of the stages. In section 3.2 the EC process is discussed in terms of its constituting activities. Use case modeling is then used for the various possible ECRs. After enumerating all the relevant use cases the activity model is developed. IDEF0 models are developed for all the constituting activities and sub-activities. Object modeling starts with the identification of all objects corresponding to every activity in the activity model. The dynamic modeling captures the object life cycle of critical objects from the object model.

\subsection{The Product development Process}

Different types of engineering changes identified in Section 1.1.5 can arise at various stages in the product design stage. Ulrich and Eppinger (2000) have clearly defined the PD process. The PD process as shown in Figure 1 starts with the 
identification of customer needs, which includes gathering raw data from customers, interpreting them in terms of customer needs, organizing the needs into hierarchy of primary, secondary and tertiary needs and then establishing their relative importance. This activity is followed by establishing target specifications for the product and then setting final specifications. ECs due to changes in customer specifications can be identified before the development of these product specifications as shown by Figure 1 . The customer needs are then analyzed to develop and select product concepts and then test those product concepts. These product concepts are then translated to engineering and technical requirements for the complete architectural design of the product. ECs can arise at this stage due to faults in translation of the customer requirements to technical requirements.

The next step is the architectural design, which involves determination of whether the product will have a 'Modular Architecture' or 'Integral Architecture', (Ulrich and Eppinger, 2000). This is followed by 'Detailed Design' wherein every component /unit/sub-component/part of the product is defined and designed in its minute details. An ECR can arise from the introduction/replacement/withdrawal of an existing component/unit/sub-component/part due to change in customer specifications or environmental or safety considerations. As shown in the Figure 1, ECs can also occur due to difficulty in fabrication or assembly. Changes can also occur during $\alpha$ - testing (InHouse) or $\beta$-testing (customer site testing). The most significant part to remember over here is that all these changes will result in changed specifications or data which is looped back to any of the preceding stages right from 'development of specifications' to 'fabrication'. 


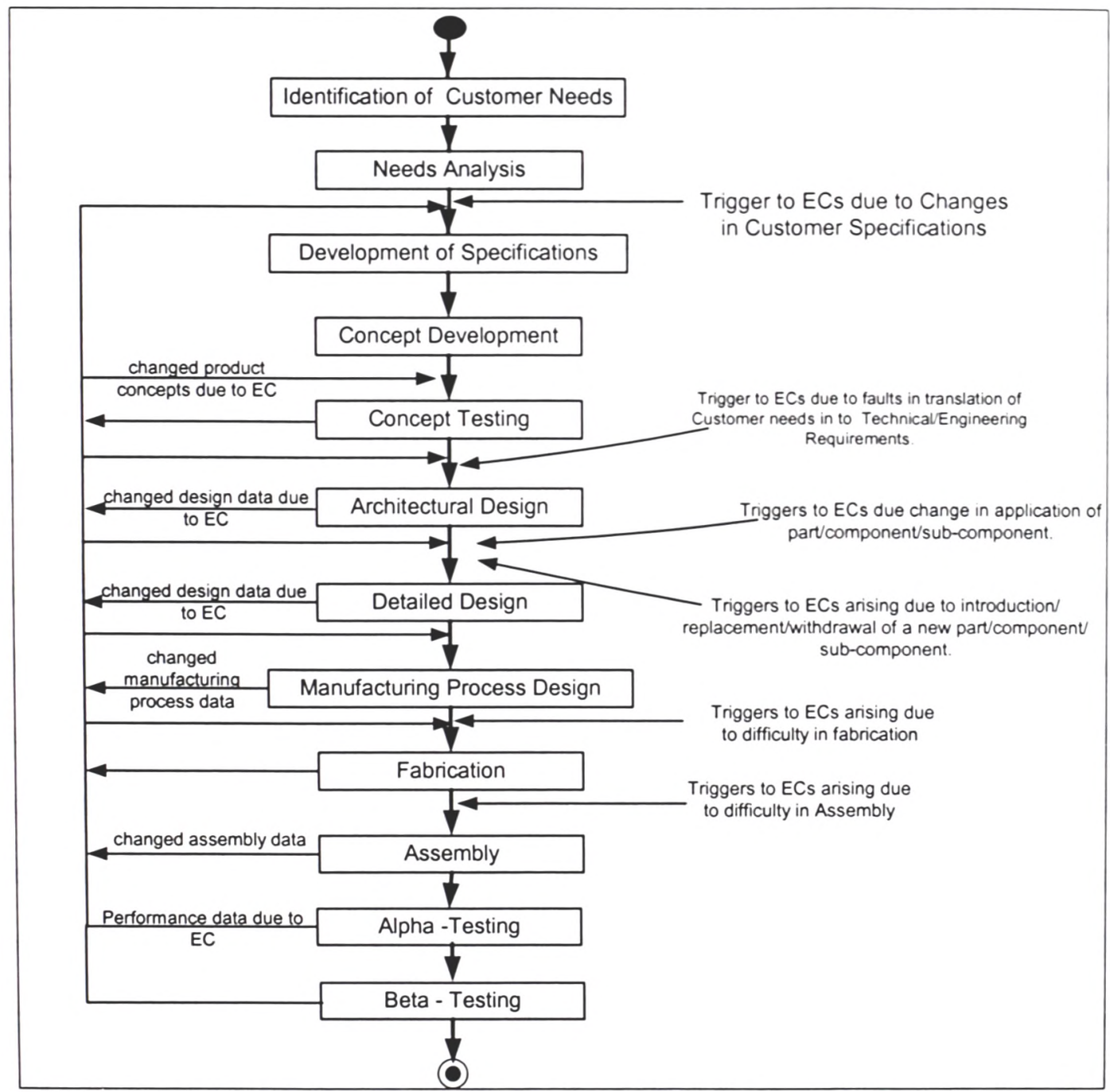

Figure 1: Various ECs relative to the Product Design Stages

\subsection{The Engineering Change Process}

The EC process model developed in this research supports extensive communication between many disciplines (functional departments) within the enterprise and also other external entities outside the enterprise. These include change requests coming from the customers' side. Almost all ECM studies agree that communication across functional lines can help avoid many problems (Balcerak \& Dale, 1998). 
Terwiesch and Loch (1999) suggested extending this inclusive communication beyond functional departments to include suppliers in order to deal with interfacing components affected by change. Literature survey suggests that communication across functional boundaries (such as between Marketing and R\&D) apply also to improving the EC process (Souder \& Moenart; 1992, 1994). The model developed as part of this research has documented a clear communication procedure in the form of an activity model clearly establishing roles between participants involved in the EC process.

The EC model is a collaborative process model between the process owner and the functional entities/allied enterprises involved. The business process of executing an $\mathrm{EC}$ is broken down into its constituting activities as shown in Figure 3. Engineering changes affect downstream activities with regard to product and processes, across departments/disciplines and allied enterprises. This research has developed an EC process model which includes the following steps: - requesting an EC, reviewing an EC, planning an EC and executing an EC. Many authors mention various activities as subsets of an EC process (Huang et al, 2000, 2001; Boznak, 1993; Baruch, 1993). This research captures the ones which are the most critical to the execution of an EC right from the process of requesting the $\mathrm{EC}$ till executing it. 


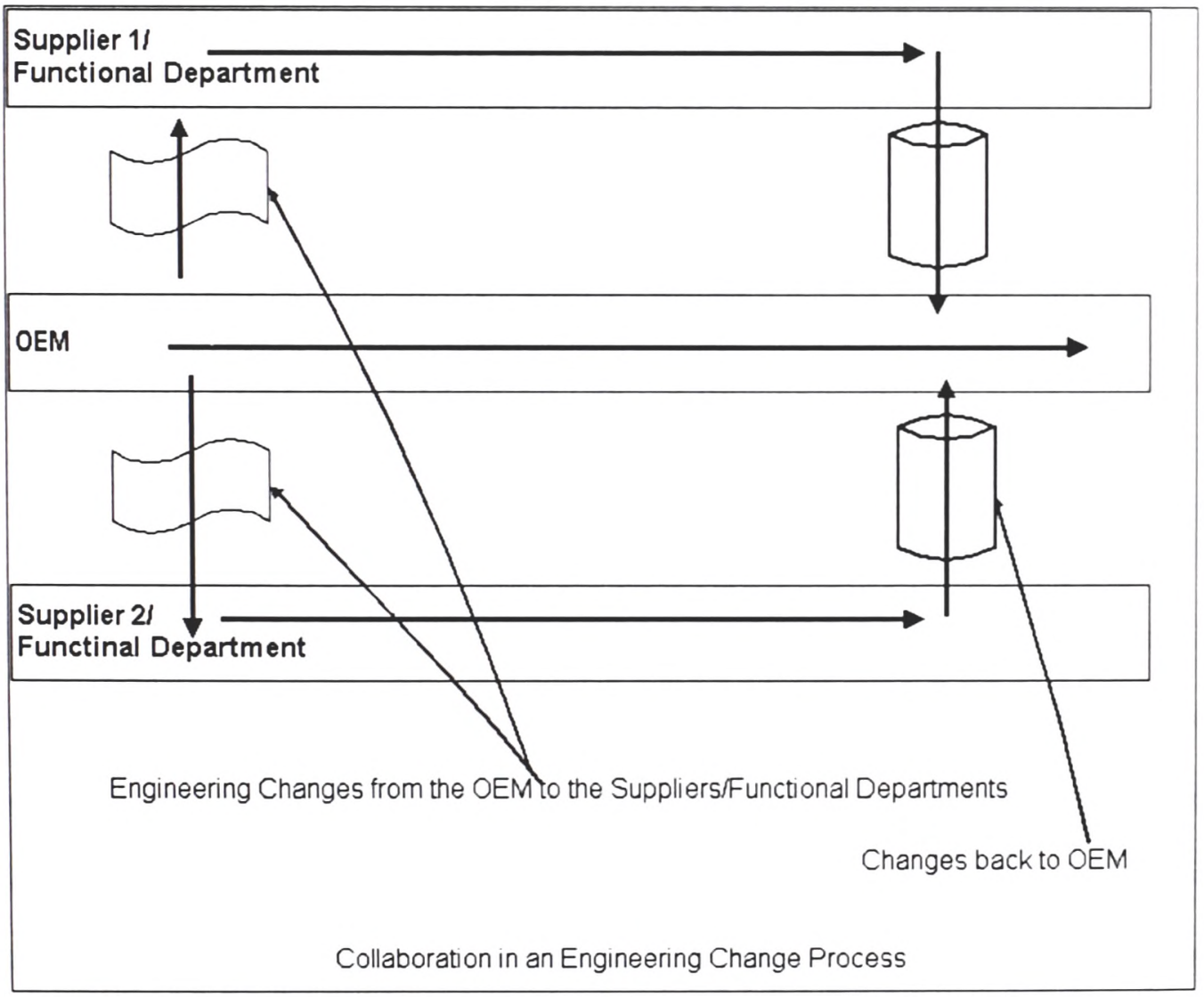

Figure 2: Collaborative EC process

An EC process in general will constitute of the steps, as shown in the Figure 3 which will include the following constituting business activities :-

1. Request an EC.

2. Review an ECR.

3. Plan for EC

4. Execute the EC.

5. Engineering Change Notification. 


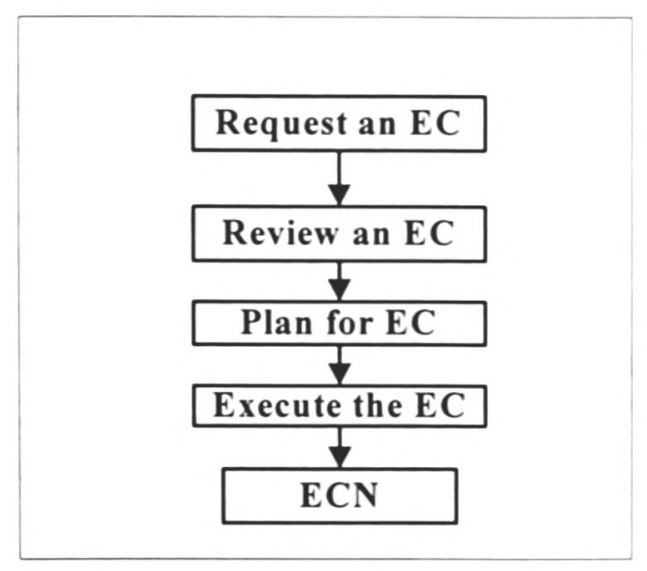

Figure 3: Activities in Engineering Change Management

All the above activities are used to develop the information model which is a generic model to manage engineering changes. Refer to Figure 4 to get an overview of the logical development of the model which starts with the use case modeling and ends with the dynamic modeling. Please refer to the activity diagram -Appendix B for executing an EC. The process starts with an ECR put forth by a customer or by an internal functionality (functional department). The ECR is routed to the EC board/committee. The next activity of. 'Review an ECR' is broken down in to technical review and economic review. Any EC related to a product design trickles down to the manufacturing processes related to its manufacture, the materials used for the manufacture and also the fabrication, assembly and also the testing of the product.

The following reviews are conducted in order to determine whether the ECR is feasible or not. The 'Design Review' determines the components/sub-components/parts that are affected by the EC. The 'Manufacturing process review' determines the effect of the EC on the manufacturing process. The change will also affect quality, which then becomes a responsibility of the quality control/assurance department for safeguarding - 


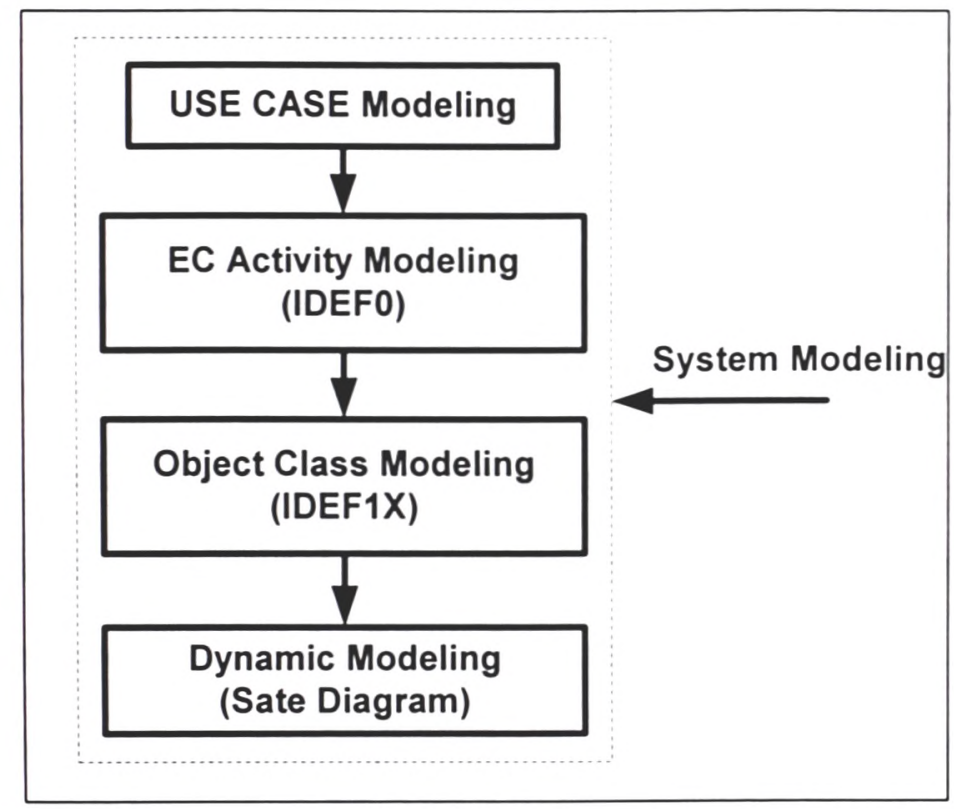

Figure 4: Overview of the Development of the Information Model

conformance to specifications as a result of the EC. The 'Quality Review' determines how the EC will impact the quality of the product / component /sub-component which is carried out by 'Quality Control'. Engineering changes and time delays are also intricately related as pointed out by Hegde et al. (1992). Engineering changes also affect the completion time of jobs thereby affecting the scheduling of the engineering changes. Thus a 'Scheduling Review' has to be conducted in order to determine the time delays that will arise due to implementation of engineering changes. Bottleneck operations and unscheduled downtime are also the factors that should be considered in the 'Scheduling Review'. After making an ECR, it is reviewed by the EC committee and the respective functional department. All the above mentioned technical reviews will serve as a right platform for the EC board to make a detailed cost-analysis which is termed as 'CostReview'. The 'Cost Review' is carried out to determine the economic feasibility of 
executing the EC. The outcome of the EC review will be an approved ECR, a rejected $\mathrm{ECR}$ or an EC quote/estimate given to the customer. Once the approval of the customer is obtained the EC board/committee will create the ECO. The ECO will then be routed to the responsible functional department(s) for implementing it. The activity of implementing the ECO can be broken down into 'incorporating the EC in fabrication', 'incorporating the EC in assembly' and 'incorporating the EC in testing'. Once the ECO is implemented an ECN is created by the department implementing the change and routed to the EC board/committee and other departments affected by the change.

The next step is the post-implementation assessment which determines whether the implemented change has met its desired goals and objectives (qualitative assessment) and quantitative assessment. The activity of quantitative assessment involves assessing the performance data derived after implementing the EC and comparing the performance data with the technical data existing before executing the EC.

\subsection{Use Case Modeling}

Use cases are written for the activities that constitute the EC process which starts from making an ECR, reviewing the ECR, planning the EC (creating the ECO) and then creating the ECN. Refer to Table 1 below for the use case of 'request an EC'. According to Jacobson et al $(1992,1994,1999)$, a use case describes all the details of a business process. The business process is thus viewed as a behaviorally related sequence of interactions performed by an actor in a dialogue with the system to provide some measurable value to the actor' (Jacobson et al. 1992, 1994). Use cases represent ways of developing an information model in terms of set of scenarios, while actors represent roles that have specific sets of responsibilities relating to use cases. 
Table 1: Use case for 'Request an EC'

\begin{tabular}{|c|c|c|}
\hline Use Case Name & \multicolumn{2}{|l|}{ Request an EC } \\
\hline Actor(s) & \multicolumn{2}{|c|}{ Customer(s), Functional department and EC board/committee. } \\
\hline Trigger & \multicolumn{2}{|c|}{ ECR initiated by any of the actors mentioned above. } \\
\hline $\begin{array}{l}\text { Typical Course } \\
\text { of Events }\end{array}$ & $\begin{array}{l}\text { Actor(s) } \\
\text { 1. This use case is initiated when actor(s) } \\
\text { make(s) a request for an EC with the } \\
\text { engineering/technical requirements, } \\
\text { expected result from the EC and order } \\
\text { specifications. }\end{array}$ & $\begin{array}{l}\text { 2. The relevant EC } \\
\text { information (type, } \\
\text { description, urgency } \\
\text { etc.) is stored in the } \\
\text { system (database). } \\
\text { 3. The system } \\
\text { generates an ECR for } \\
\text { the corresponding } \\
\text { request made by the } \\
\text { actors. }\end{array}$ \\
\hline $\begin{array}{l}\text { Alternate Course } \\
\text { of Events }\end{array}$ & \multicolumn{2}{|c|}{ None at this time. } \\
\hline Precondition & \multicolumn{2}{|l|}{ ECRs can be submitted by the actor(s) only. } \\
\hline Post Condition & \multicolumn{2}{|c|}{ An ECR is submitted by the customer/functional Department. } \\
\hline
\end{tabular}


Table 2: Use Case for 'Review the ECR'

\begin{tabular}{|c|c|c|}
\hline USE CASE NAME & \multicolumn{2}{|c|}{ Review the EC Request } \\
\hline Actor(s) & EC board/committee \& Functional & epartments. \\
\hline Pre Condition & ECR submitted by the customer/fur & ctional department. \\
\hline Typical Course of Events & $\begin{array}{l}\text { Actor(s) } \\
\text { 1. The EC board receives the ECR } \\
\text { with the EC item. } \\
\text { 2. The EC board conducts a } \\
\text { design change review which will } \\
\text { also involves engineering and } \\
\text { design. } \\
\text { 3. The design and engineering } \\
\text { department submit the results of } \\
\text { the design review to the system } \\
\text { (database). } \\
\text { 5. The EC board and the } \\
\text { production department conduct } \\
\text { the manufacturing process review } \\
\text { to determine the changes in the } \\
\text { manufacturing processes due to } \\
\text { the EC. } \\
\text { 6. The EC board and the } \\
\text { production department submit the } \\
\text { results of the manufacturing } \\
\text { process review to the system. } \\
\text { 8. The EC board and inventory } \\
\text { control conduct the materials } \\
\text { review to determine the changes } \\
\text { in raw materials/BOM. } \\
\text { 9. The EC board and the } \\
\text { inventory control submit the } \\
\text { results of the materials review to } \\
\text { the system. } \\
\text { 11. The EC board and quality } \\
\text { control conduct quality review to } \\
\text { determine the impacts/changes on } \\
\text { quality due to the EC. } \\
\text { 12. The EC board and quality } \\
\text { control submit the results of the } \\
\text { quality review to the system. }\end{array}$ & $\begin{array}{l}\text { 7. The system records } \\
\text { results of the } \\
\text { manufacturing } \\
\text { processes review. }\end{array}$ \\
\hline
\end{tabular}


Table2: Use Case for 'Review the ECR (contd)

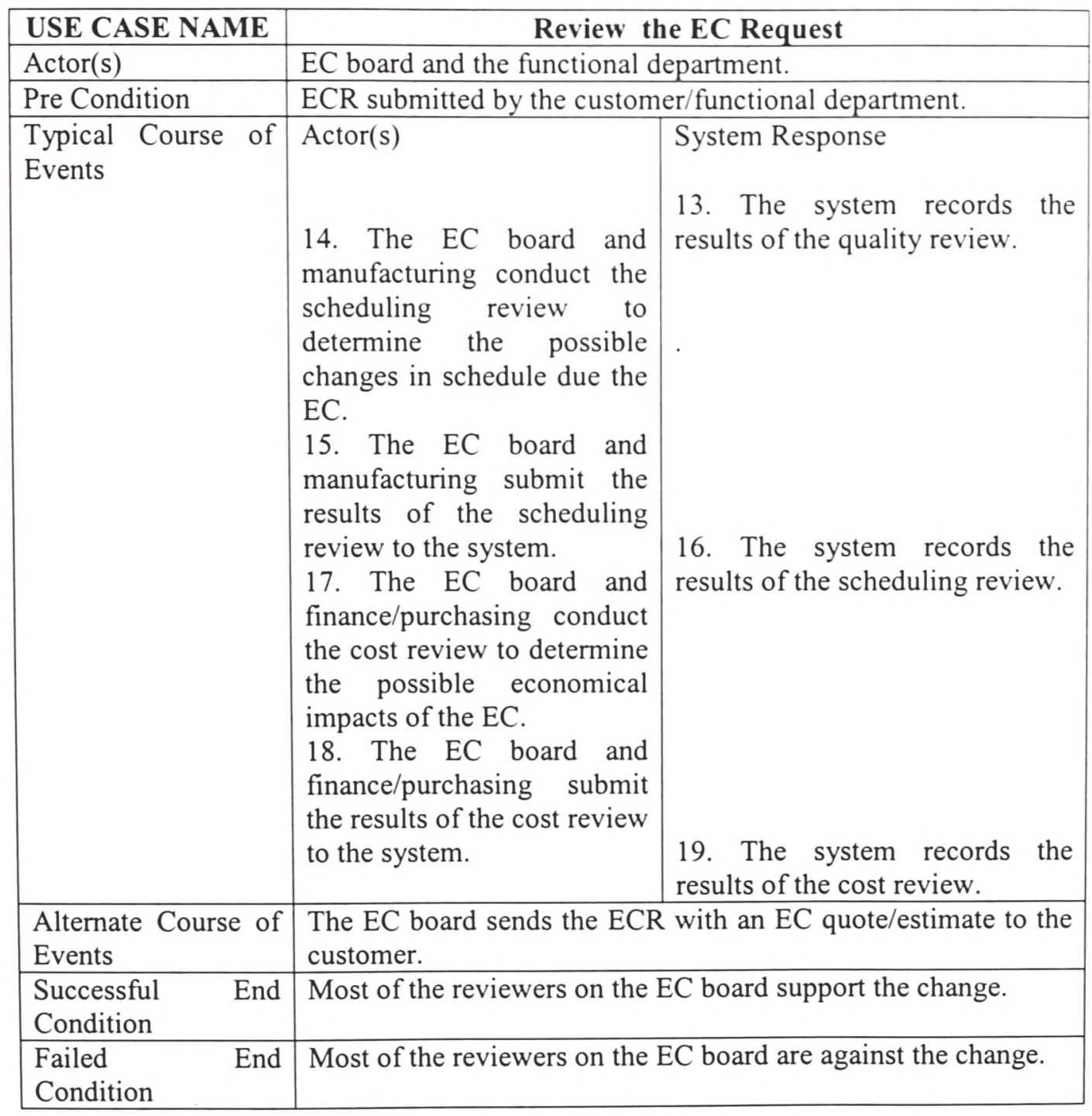




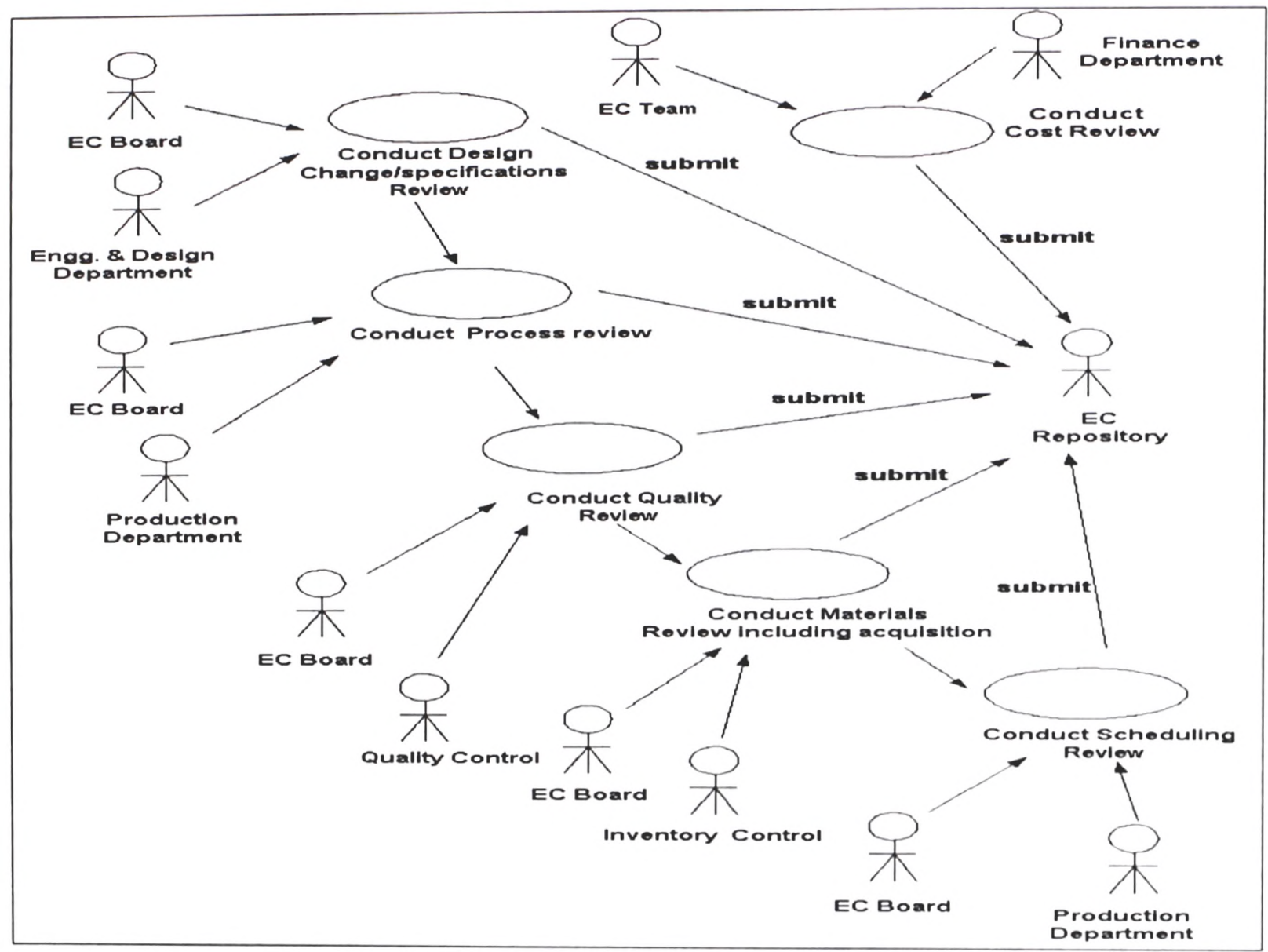

Figure 5: Use Case diagram of 'Review an EC' 
Table 3: Use Case for 'Plan for EC'

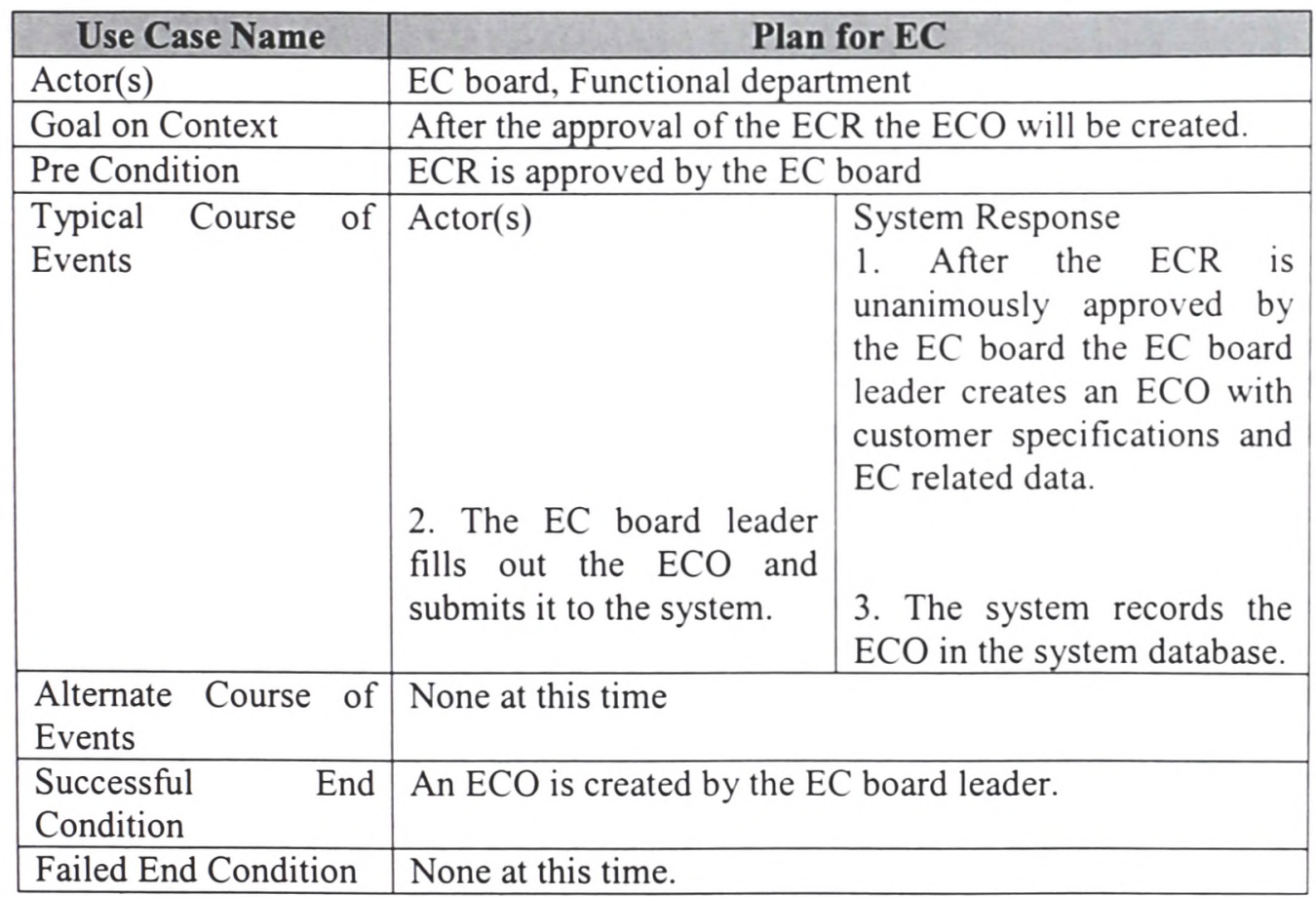

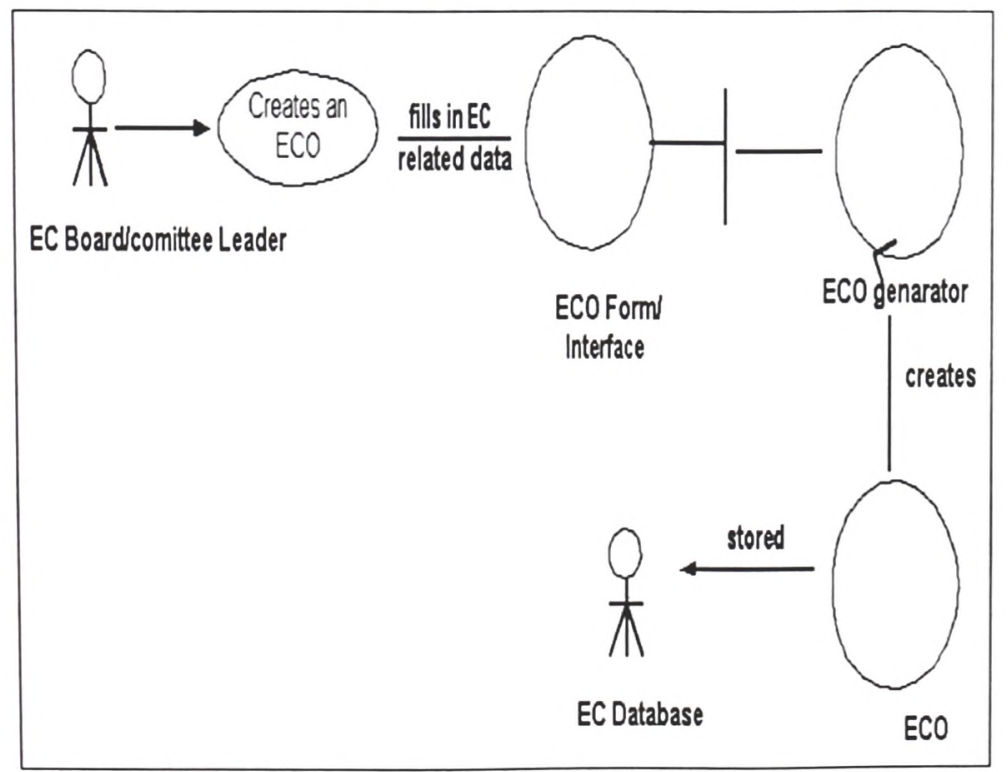

Figure 6: Use Case diagram for 'Create an ECO' 
Table 4: Use Case for 'Execute the ECO'

\begin{tabular}{|c|c|c|}
\hline CASE NAME & \multicolumn{2}{|c|}{ Execute the EC } \\
\hline Actor(s) & \multicolumn{2}{|c|}{ EC board and Functional departments. } \\
\hline Trigger & \multicolumn{2}{|c|}{ ECO created by the EC board leader. } \\
\hline $\begin{array}{l}\text { Typical Course of } \\
\text { Events }\end{array}$ & $\begin{array}{l}\text { Actor(s) } \\
\text { 1. This use case starts when the } \\
\text { EC board leader routes the ECO } \\
\text { to the concerned department. This } \\
\text { will be functionalized ECO. } \\
\text { 3. The concerned department(s) } \\
\text { implement(s) the change } \\
\text { according to the ECO. } \\
\text { 4. While implementing the } \\
\text { change the implementing } \\
\text { department(s) also prepares the } \\
\text { EC progress report and submits it } \\
\text { to the system. } \\
\text { 6. The implementing department } \\
\text { generates the ECN once the EC is } \\
\text { completely implemented. } \\
7 . \text { The implementing department } \\
\text { routes the ECN to the EC team } \\
\text { and to other departments effected } \\
\text { by the change and submits the } \\
\text { ECN to the system. }\end{array}$ & $\begin{array}{l}\text { 5. The system records } \\
\text { the EC progress report in } \\
\text { the EC database to be } \\
\text { archived later in the } \\
\text { future. }\end{array}$ \\
\hline $\begin{array}{lll}\text { Alternate } & \text { Course of } \\
\text { Events } & & \end{array}$ & \multicolumn{2}{|l|}{ None at this time } \\
\hline $\begin{array}{ll}\text { Successful } & \text { End } \\
\text { Condition } & \end{array}$ & \multicolumn{2}{|l|}{ ECN creation. } \\
\hline Failed End Condition & \multicolumn{2}{|c|}{$\begin{array}{l}\text { If the EC is not completely implemented then the status will } \\
\text { be mentioned as incomplete/in-progress on the EC progress } \\
\text { report(s). }\end{array}$} \\
\hline
\end{tabular}




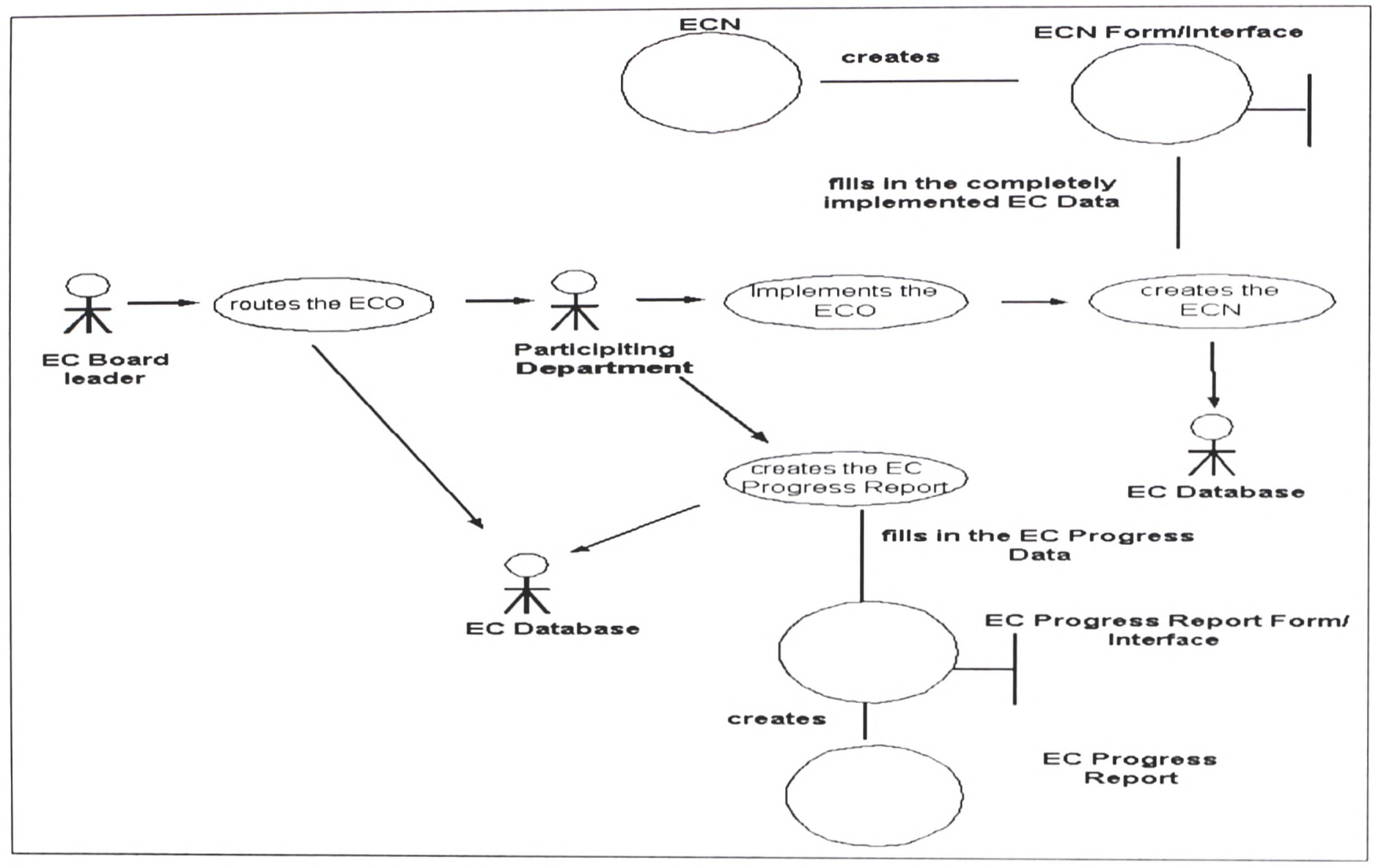

Figure 7: Use Case diagram of 'Execute the EC' 
Table 5: Use Case of 'Post Implementation Assessment'/ECN'

\begin{tabular}{|c|c|c|}
\hline CASE NAME & \multirow{2}{*}{\multicolumn{2}{|c|}{$\begin{array}{l}\text { Post Implementation Assessment/ECN } \\
\text { EC board/committee and functional department }\end{array}$}} \\
\hline Actor(s) & & \\
\hline Goal on Context & \multicolumn{2}{|c|}{$\begin{array}{l}\text { To asses the results of the implemented EC both } \\
\text { quantitatively (scrap, rework etc.) and qualitatively } \\
\text { (achievement of goals/objectives). }\end{array}$} \\
\hline Trigger & \multicolumn{2}{|c|}{ ECN received by the EC board/committee leader. } \\
\hline Pre Condition & \multicolumn{2}{|c|}{ The EC has to be executed. } \\
\hline $\begin{array}{l}\text { Typical Course of } \\
\text { Events }\end{array}$ & $\begin{array}{l}\text { Actor(s) } \\
\text { 1. This use case begins when the } \\
\text { EC board/committee leader and } \\
\text { the concerned functional } \\
\text { departments receive the ECN. } \\
\text { 2. Upon receipt of the ECN the } \\
\text { EC team conducts the qualitative } \\
\text { assessment of the EC. } \\
\text { 3. The results of the qualitative } \\
\text { assessment are submitted to the } \\
\text { system. } \\
\text { 5. The EC board/committee } \\
\text { conducts the quantitative } \\
\text { assessment of the EC and } \\
\text { measures it against the } \\
\text { performance data. } \\
6 \text {. The EC board/committee } \\
\text { submits the performance data to } \\
\text { the system. }\end{array}$ & $\begin{array}{l}\text { 7. The system records } \\
\text { the performance data. } \\
\text { 8. The use case ends } \\
\text { when the system } \\
\text { records all the } \\
\text { relevant details of the } \\
\text { EC and generates the } \\
\text { EC result report. }\end{array}$ \\
\hline $\begin{array}{l}\text { Alternate Course of } \\
\text { Events }\end{array}$ & \multicolumn{2}{|c|}{$\begin{array}{l}\text { If the post implementation assessment is negative then the } \\
\text { feedback along with the necessary alterations to the } \\
\text { engineering change are sent back to the concerned } \\
\text { functionalities responsible for executing the change. }\end{array}$} \\
\hline $\begin{array}{l}\text { Successful } \\
\text { Condition }\end{array}$ & \multicolumn{2}{|c|}{$\begin{array}{l}\text { The outcome of this step is a set of performance data that } \\
\text { gives valuable insights to the changes due to the executed } \\
\text { ECs and the EC result report }\end{array}$} \\
\hline Failed End Condition & \multicolumn{2}{|c|}{$\begin{array}{l}\text { The new performance data indicates failure or incapability } \\
\text { to achieve the required results in terms of technical } \\
\text { requirements or customer specifications. }\end{array}$} \\
\hline
\end{tabular}




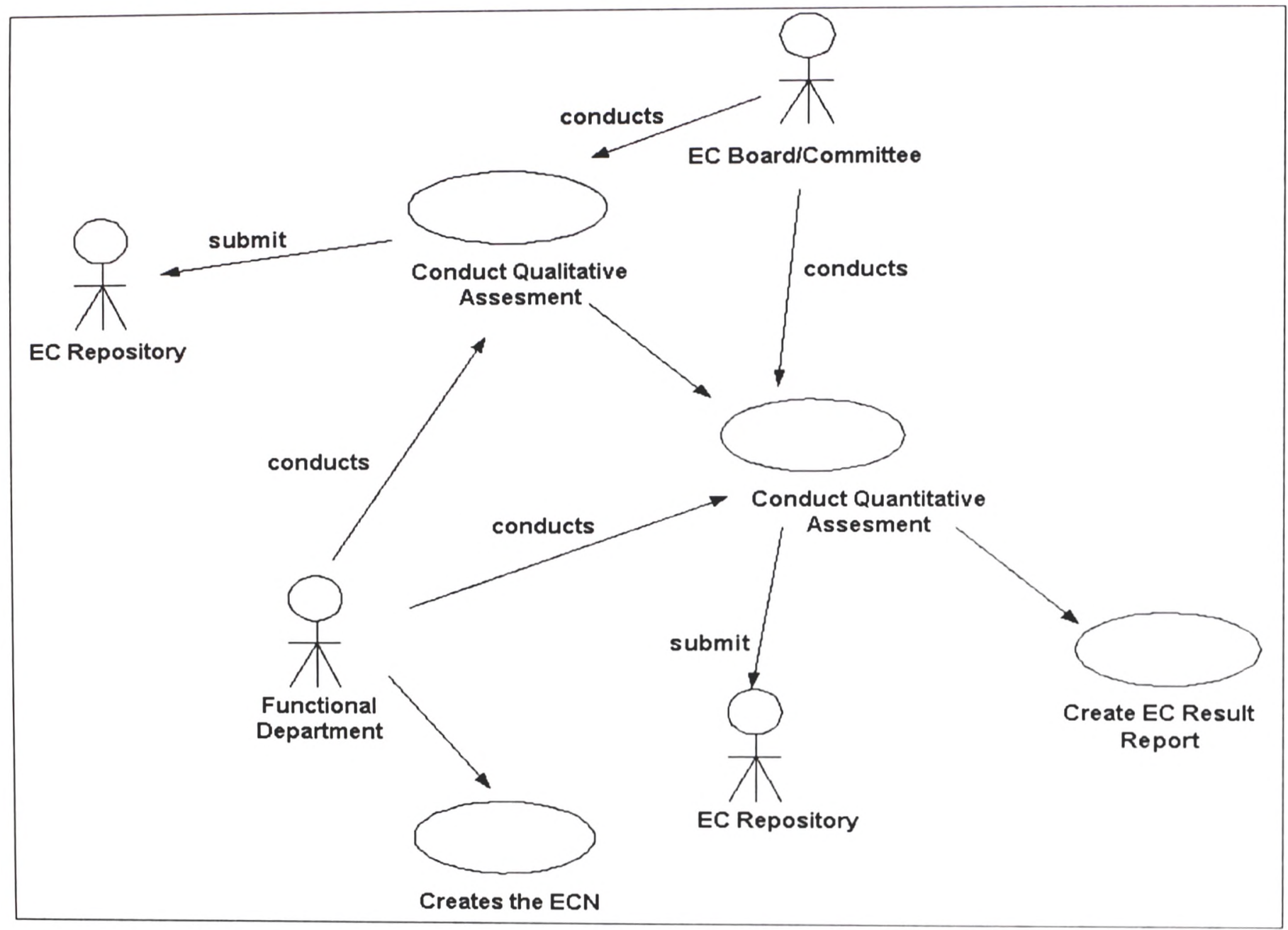

Figure 8: Use Case diagram of 'Post-Implementation Assessment/ECN' 


\subsection{ACTIVITy Modeling}

The first step was to clearly depict the different types of change requests in terms of the use cases mentioned above from Table 1 through Table 5. These are the activities that have to be carried out while executing an EC. The activities depicted in the use cases are broken down in to its logical sub-activities so as to develop a comprehensive activity model for the execution of engineering changes. The IDEF0 diagram for managing engineering changes is shown in Figure 9.

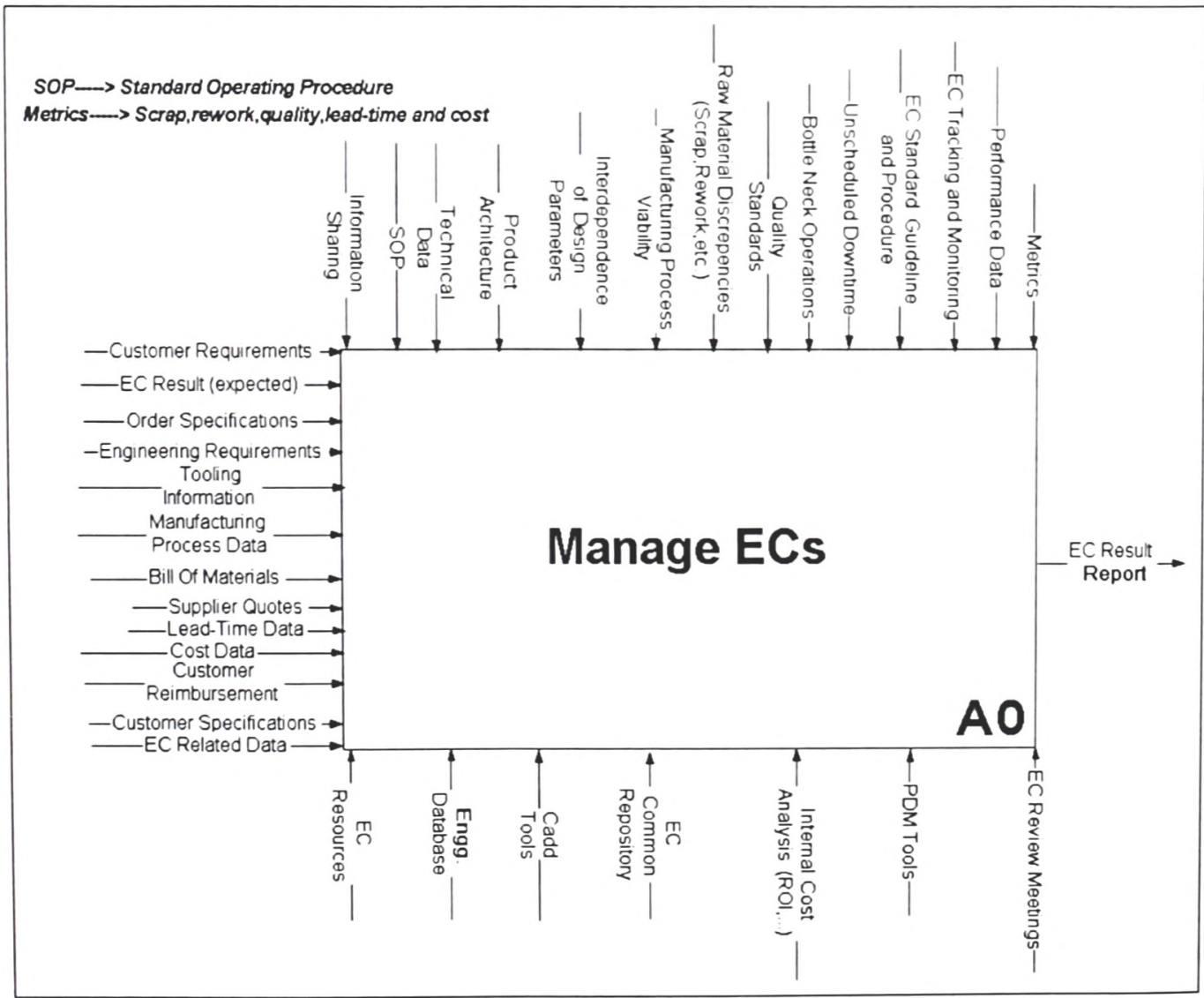

Figure 9: IDEF0 diagram of 'Managing an Engineering Change' 
The model developed for the execution of an EC provides a complete overview of an EC process model that can be developed using the activities represented by the node tree in Figure 10 . A21, A22, A23, A24, A25 \& A26 (child nodes of A2) are the child activities of the parent activity A2 (parent node A2). A421, A422 and A423 are the child nodes of the sub-activity A42. A51 and A52 are child nodes of parent node A5.

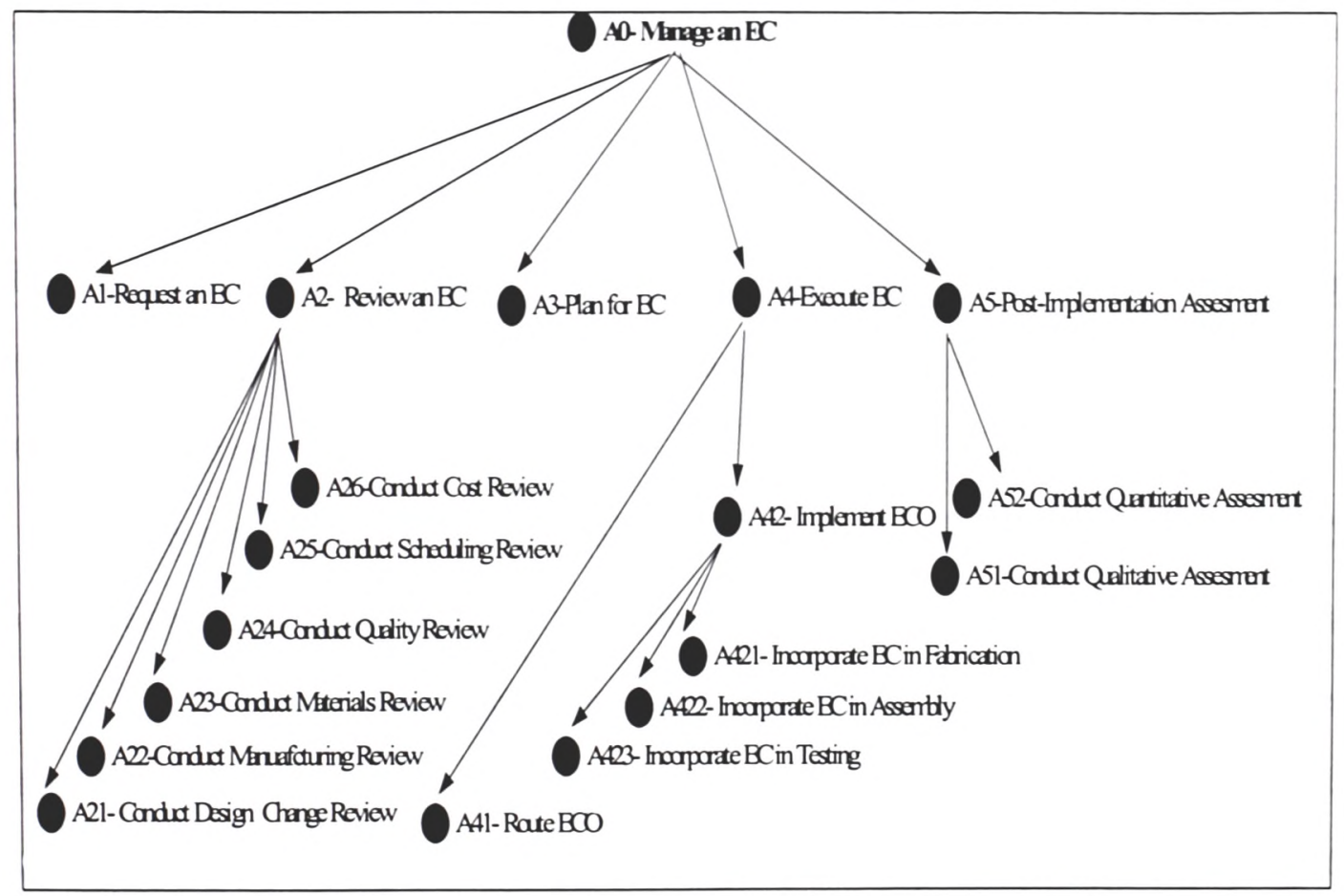

Figure 10: Hierarchical diagram of activities to mange ECs.

The EC activities mentioned have been analyzed for the inputs, outputs, resources and mechanisms that are required to execute them and then IDEF0 diagrams have been drawn for every activity. The first and most obvious step after identifying an EC is to convert it in to an ECR. Every ECR is characterized by the following inputs: - customers' 
requirements which are the trigger for initiating an EC, the intended EC result, the engineering/technical requirements of the $\mathrm{EC}$ and order specifications as mentioned by the customer. The mechanisms, which have a direct control over all these EC activities, are $\mathrm{CAD}$ tools $(\mathrm{CAD} / \mathrm{CAM} / \mathrm{CAPP} / \mathrm{CAE}$ software), engineering database, $\mathrm{EC}$ common repository and the engineering resources/equipments that play a vital role in the execution of each and every activity. Whenever there is an ECR/RFQ (Request for Quotation) submitted by the customer for an EC three important questions should be answered by the EC Board/committee:

Q1: Can the EC be executed?

Q2: What will be the technical implications- manufacturing processes affected, materials (BOM) affected due to the change, quality impacts, scheduling impacts?

Q3: What will be the cost incurred?

The output of the EC review will be either in the form of rejected ECRs, EC quotes/estimates to customers who will bear the cost of the EC or the approved ECRs themselves which are ready to be implemented. Those ECRs that have to be modified are sent back for modifications to the requesting party. The activity of executing the EC will have an output of EC progress report submitted to the EC board/committee. In case of completely implemented engineering changes, an ECN is issued to inform all the concerned entities about the implementation of the change. The complete Activity model is shown in Figure 11. 


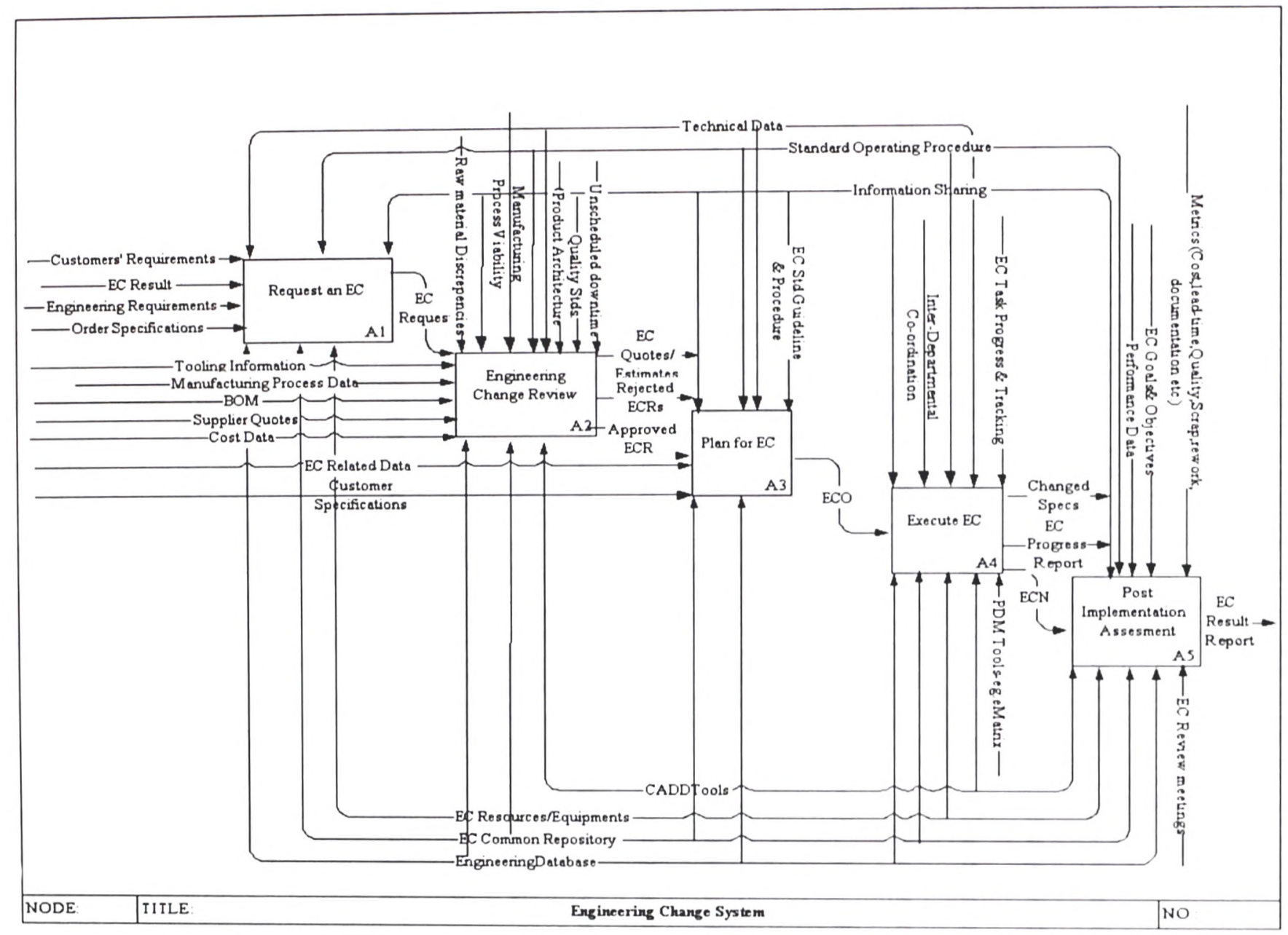

Figure 11: The IDEF0 Activity Model for 'Managing Engineering Changes' 
Every activity in Figure 11 shown above will be depicted in to its sub activities starting with activity A2. Refer Figure 12 to see the logical break down of the activity A2. This activity starts with the design review. The design review analyzes the product design for any design change, followed by the manufacturing process review that will take in to consideration the manufacturing processes that will be affected. Apart from the above mentioned reviews, other factors that would be affected by change will be the materials used for the manufacturing. The BOM and supplier quotes will act as inputs for the materials review to be conducted as part of the EC review. The result of a materials review will be a modified BOM. The quality control department will also take in to account the impacts on the quality of the product due to the EC.

One more aspect to be considered will be the effect on the scheduling (Hegde, 1992), since it is really important to determine whether the EC can be implemented on time. Last but not the least, the conclusions from the above mentioned reviews will provide as the right base to conduct a cost analysis/cost review to come up with an estimate or quote to be given to the customer as costs to be incurred to implement the EC. The decomposed IDEF0 model for the activity of 'review an engineering change' into its sub-activities is shown in Figure 12. 


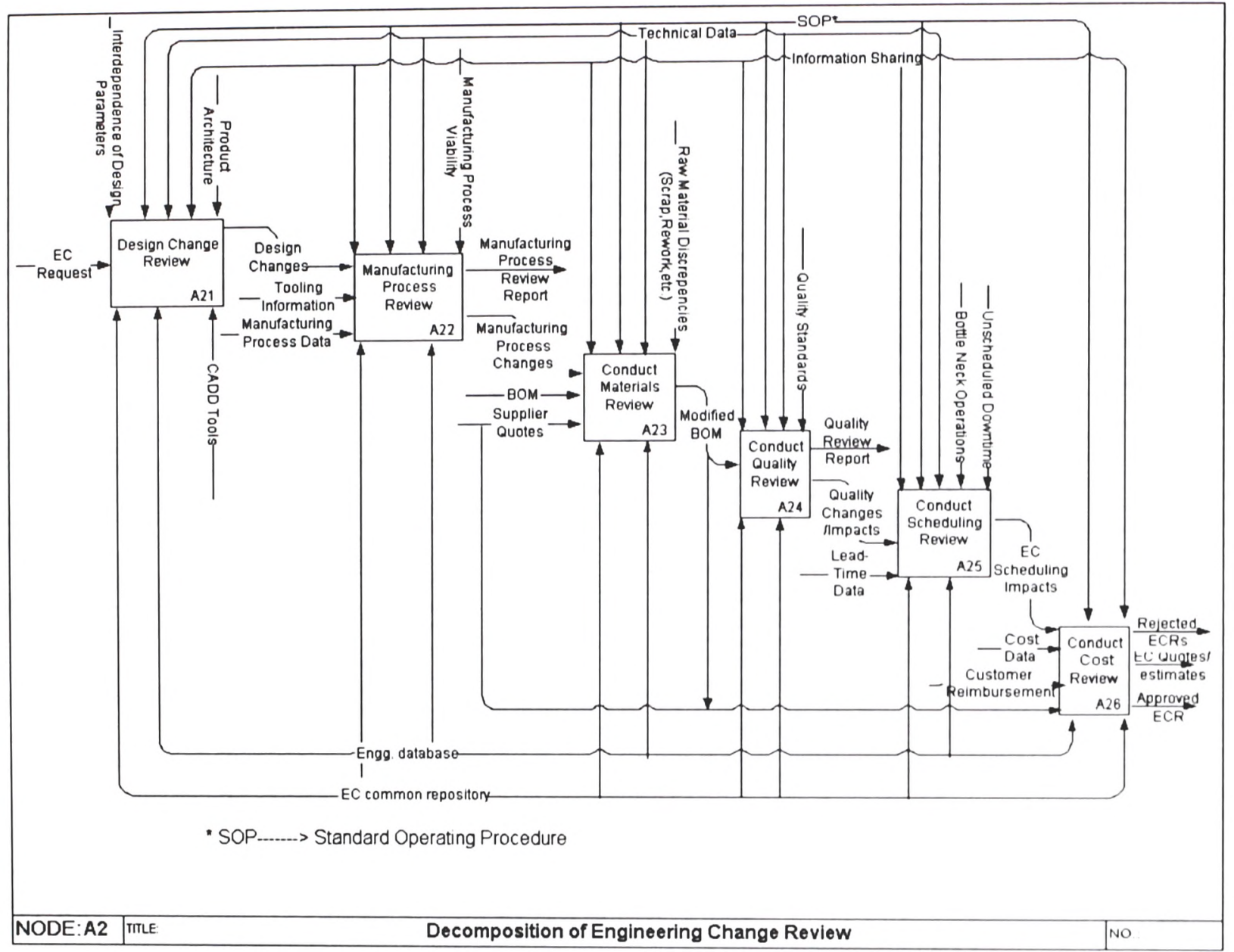

Figure 12: The decomposed IDEF0 Model of 'Review an Engineering Change' 


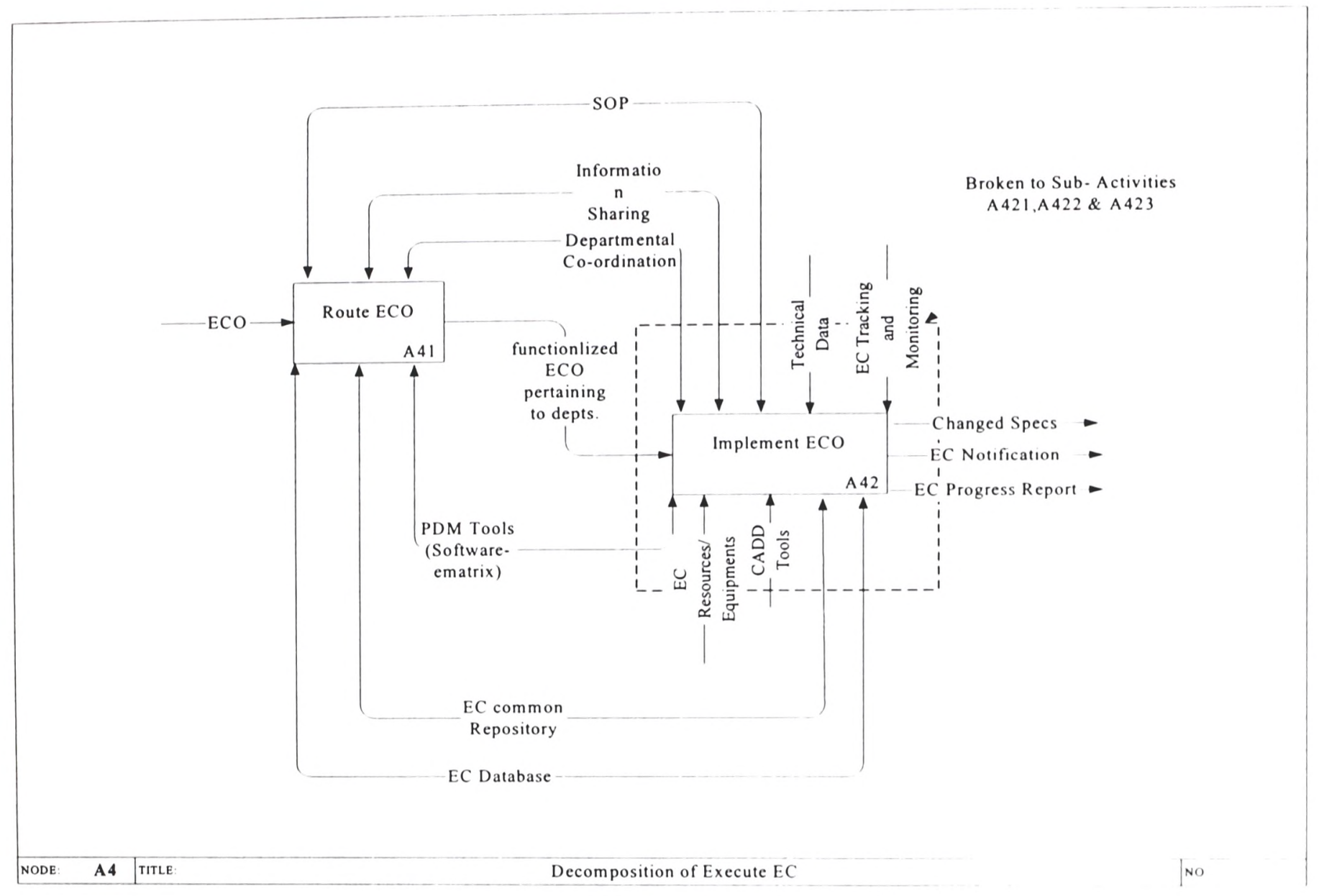

Figure 13: The IDEF0 Model of 'Execute an EC' 


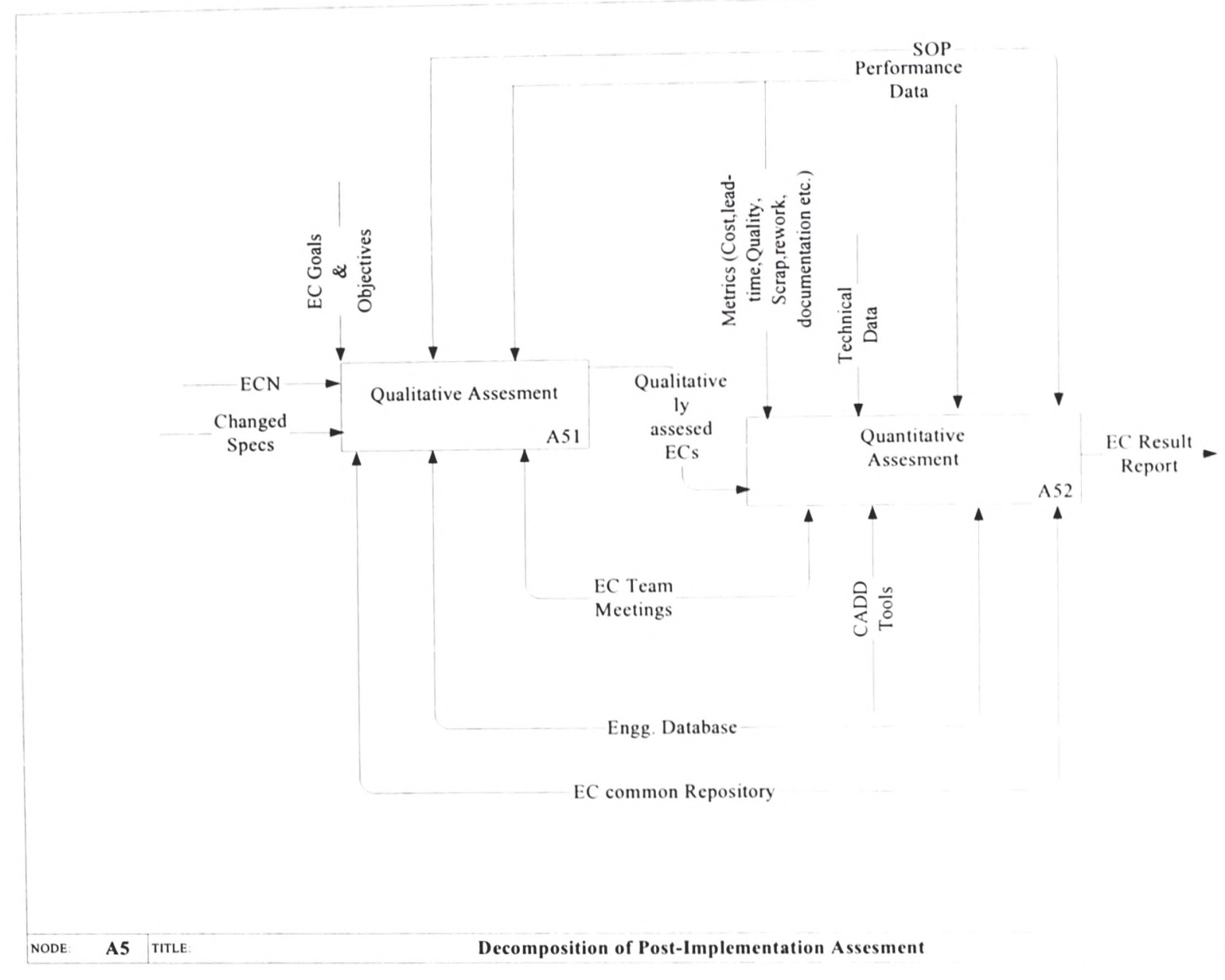

Figure 14: The IDEF0 Functional Model of 'Post-Implementation Assessment' 
Please refer Figure 15. The sub-activity A42 (implement the ECO) can be broken down into its logical sub-activities - i.e. 'implement EC in fabrication', 'implement EC in assembly' and 'implement EC in testing'. The IDEF0 diagram for the above mentioned sub-activity is as shown in Figure 15. An EC can affect the fabrication of a part/subcomponent/component. The function of making a product/part/component from its constituting raw-materials is called 'fabrication'. The inputs to this activity are the rawmaterials that go into its fabrication. Material properties act as a control over this activity. An EC can thus affect the fabrication of the component and the EC has to be incorporated in the process of fabrication. Fabrication can also give rise to modifications that need to be made to the customer specifications. The output of this sub-activity will be a fabricated part/component/sub-component which goes into assembly. After assembly the part/component/sub-component has to be tested in accordance with quality standards and customer specifications. The most important fact to remember here is that fabrication, assembly and testing can all result in modifications that need to be made to the customer specifications depending on the type of EC as shown in Figure 15.

The decomposed IDEF0 diagram of every activity right from A1 to A5 is used to construct the activity model. The model incorporates in detail the constraints, the inputs and the outputs of every sub-activity. The logical decomposition of every activity gives rise to the final activity model which then will be further used to develop the object model for executing an EC. 


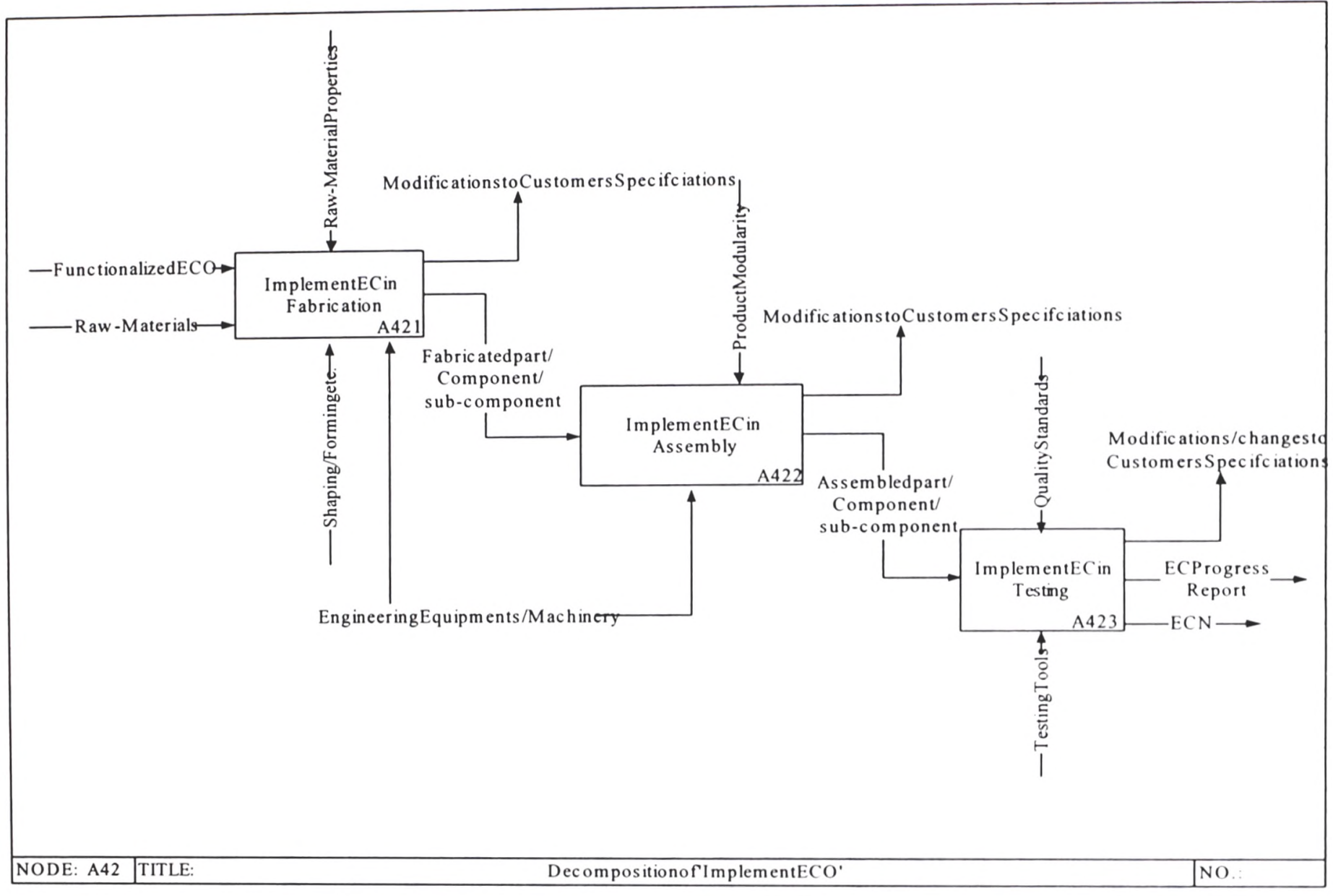

Figure 15: The IDEF0 Functional Model for decomposition of 'Implement ECO' 


\subsection{OBJect Modeling}

Object modeling has two purposes of capturing all objects in the EC process from the activity model and defining these objects in terms of their attributes. Object modeling also helps to create a seamless transition from a business process to an ECM information system. Objects were extracted from every activity of the activity model right from 'request an EC' to 'execute an EC.'

Object class diagrams were drawn for objects derived from every activity and their cardinalities were shown in the object class diagrams. Every object was defined in terms of its attributes. Table 6 shows a list of all objects that have been identified from the activity model. The first column of shows the name of the data entity, the second column shows the object type and the third column shows the activity from which the object is extracted. From the comprehensive list of objects as shown in Table 6 the objects will be segregated depending on which activity they belong to and then these objects were defined in terms of their attributes. For instance the analysis of the first activity 'request and EC' resulted in identification of the following objects: ECR, customer, order specifications, functional department and EC board. Refer to Table 8 for the attribute table of the object ECR. The primary key of the object ECR is an ECR number which is a unique identification number to identify a particular ECR. The other important attributes are the change description, request type, EC title and the status of the ECR. 
Table 6: Complete object list from Activity Model

\begin{tabular}{|l|l|l|}
\hline \multicolumn{1}{|c|}{$\begin{array}{c}\text { Entity name from activity } \\
\text { model }\end{array}$} & \multicolumn{1}{|c|}{ Object type } & \multicolumn{1}{c|}{$\begin{array}{c}\text { Activity from which object } \\
\text { originates }\end{array}$} \\
\hline ECR & Entity & 'request an engineering change' \\
\hline Customer & Entity & 'request an engineering change' \\
\hline Specifications & Entity & 'request an engineering change' \\
\hline EC result & Entity & 'request an engineering change' \\
\hline EC Quote & Entity & 'review an engineering change \\
\hline EC review & Entity & 'review an engineering change' \\
\hline EC review report & Entity & 'review an engineering change' \\
\hline EC board & Entity & $\begin{array}{l}\text { 'review an engineering change' } \\
\text { 'plan for engineering change' }\end{array}$ \\
\hline EC goal & Entity & 'Post implementation assessment' \\
\hline Changed specification & Entity & 'execute an engineering change' \\
\hline Engineering process & Entity & 'review an engineering change' \\
\hline Product item & Entity & $\begin{array}{l}\text { 'request an engineering change' } \\
\text { 'execute an engineering change' }\end{array}$ \\
\hline Supplier quote & & $\begin{array}{l}\text { 'review an engineering change } \\
\text { request' }\end{array}$ \\
\hline EC result report & Entity & 'post implementation assessment' \\
\hline EC board & Entity & 'review an engineering change' \\
\hline EC item & Entity & 'execute an engineering change' \\
\hline ECN & Entity & 'execute an engineering change' \\
\hline EC progress report & Entity & 'execute an engineering change' \\
\hline ECO & Entity & 'plan for engineering change' \\
\hline EC cost & Entity & 'review an engineering change \\
\hline BOM & Entity & 'review an engineering change' \\
\hline EC board member & Entity & 'review an engineering change' \\
\hline Functional Department & Entity & $\begin{array}{l}\text { 'review an engineering change' } \\
\text { 'execute an engineering change' }\end{array}$ \\
\hline EC review report & 'review an engineering change' \\
\hline EC project & Entity & 'plan for engineering change' \\
\hline & Entity &
\end{tabular}

Table 7: List of objects for the activity 'Request an EC'

\begin{tabular}{|l|l|}
\hline \multicolumn{1}{|c|}{ Entity name } & Object Type \\
\hline ECR & Entity \\
\hline EC Board/committee & Entity \\
\hline EC Committee leader & Entity \\
\hline Functional Departments & Entity \\
\hline Customer(s) & Entity \\
\hline
\end{tabular}


Table 8: Attribute table of the object 'ECR'

\begin{tabular}{|l|l|}
\hline \multicolumn{1}{|c|}{ Object Name } & \multicolumn{1}{c|}{ Engineering Change Request (ECR) } \\
\hline Definition & $\begin{array}{l}\text { A request submitted in order to bring into effect an engineering } \\
\text { change to a particular product, part, component, sub-component, } \\
\text { process, supplies or even a process. }\end{array}$ \\
\hline Attribute Name & Definition \\
\hline ECR \# & $\begin{array}{l}\text { A unique identification number for identifying an EC. This will be } \\
\text { used as the primary key for the object ECR }\end{array}$ \\
\hline EC Title & The title describing the EC in short/ name of the ECR. \\
\hline Request Type & $\begin{array}{l}\text { Mentions the type of the EC-customer specified, design change } \\
\text { process change, materials change etc. }\end{array}$ \\
\hline Department ID & $\begin{array}{l}\text { The department ID of the functional department initiating the ECR. } \\
\text { This can also act as the Alternate Key (AK) for the object. }\end{array}$ \\
\hline $\begin{array}{l}\text { Change } \\
\text { Description }\end{array}$ & $\begin{array}{l}\text { Every EC can be described in terms of its technical requirements, } \\
\text { customer order specifications and expected EC result. }\end{array}$ \\
\hline Status & $\begin{array}{l}\text { Every ECR is reviewed for its feasibility and the end result of this is } \\
\text { an ECR that can have a status of [approved/rejected/modified]. }\end{array}$ \\
\hline Request Date & Date the request was submitted. \\
\hline Approval Date & Date indicating the approval of the request. \\
\hline
\end{tabular}

Table 9: Sample of an 'ECR'

\begin{tabular}{|c|c|}
\hline \multicolumn{2}{|r|}{ GYC Engineering Change Request (ECR) } \\
\hline ECR \#: & 002 \\
\hline Submitted by & Delta Industries (Customer) \\
\hline Title & MPS Cost Reduction \\
\hline Request date & $03 / 04 / 2004$ \\
\hline Status & Approved \\
\hline Approval Date & $03 / 29 / 2004$ \\
\hline $\begin{array}{l}\text { Change } \\
\text { Description }\end{array}$ & $\begin{array}{l}\text { 1. Reduce efficiency requirement in section } 6.2 \text { from } 65 \% \text { to } 60 \% \text {. } \\
\text { 2. Remove the requirements that the } 5 \text { VSB output stay on during a } \\
\text { power supply shut down due to an over temperature condition. }\end{array}$ \\
\hline Order ID & The order number corresponding to the engineering change. \\
\hline Item ID & $\begin{array}{l}\text { The ID for the item (process, product, component, etc.)which } \\
\text { undergoes the EC }\end{array}$ \\
\hline Cost & The estimated cost for the engineering change. \\
\hline Approved by & The approval of the EC board leader for the engineering change. \\
\hline
\end{tabular}


Table 10: Attribute table of the object 'EC board/committee'

\begin{tabular}{|l|l|}
\hline \multicolumn{1}{|c|}{ Object Name } & \multicolumn{1}{c|}{ Engineering Change Board/Committee } \\
\hline Definition & $\begin{array}{l}\text { The EC change committee that looks over the management } \\
\text { of ECs. Functionalities- reviewing, approving, tracking and } \\
\text { implementing ECs. }\end{array}$ \\
\hline \multicolumn{1}{|c|}{ Attribute Name } & \multicolumn{1}{|c|}{ Definition } \\
\hline $\begin{array}{l}\text { EC } \\
\text { board/committee_ID(PK) }\end{array}$ & $\begin{array}{l}\text { A unique identification number for identifying EC } \\
\text { committee. This will be used as the primary key for the } \\
\text { object ECR }\end{array}$ \\
\hline EC board leader & $\begin{array}{l}\text { The leader of the EC board. Usually lead by the head of a } \\
\text { functional department. }\end{array}$ \\
\hline
\end{tabular}

Table 11: Attribute table of the object 'EC board/committee leader'

\begin{tabular}{|l|l|}
\hline \multicolumn{1}{|c|}{ Object Name } & \multicolumn{1}{c|}{ Engineering Change Board/Committee Leader } \\
\hline Definition & The leader of the EC committee. \\
\hline \multicolumn{1}{|c|}{ Attribute Name } & \multicolumn{1}{c|}{ Definition } \\
\hline SSN(PK) & $\begin{array}{l}\text { A unique identification number for identifying EC committee } \\
\text { leader. This will be used as the primary key for the object EC } \\
\text { board leader. }\end{array}$ \\
\hline Department ID & $\begin{array}{l}\text { The department ID of the functional department from which } \\
\text { the EC board leader is. }\end{array}$ \\
\hline Employee ID & The employee ID of the EC board Leader. \\
\hline Designation & $\begin{array}{l}\text { The designation of the EC board leader in the functional } \\
\text { department. }\end{array}$ \\
\hline
\end{tabular}

Table 12: Attribute table of the object 'Functional Department'

\begin{tabular}{|l|l|}
\hline \multicolumn{1}{|c|}{ Object Name } & \multicolumn{1}{c|}{ Functional Department } \\
\hline Definition & $\begin{array}{l}\text { The functional departments which can submit an ECR. } \\
\text { Example- design, manufacturing, inventory control, quality } \\
\text { control, production, marketing etc. }\end{array}$ \\
\hline \multicolumn{1}{|c|}{ Attribute Name } & \multicolumn{1}{c|}{ Definition } \\
\hline Department_ID (PK) & $\begin{array}{l}\text { The department ID of the functional department initiating the } \\
\text { ECR. This is the primary key for the object- functional } \\
\text { department. }\end{array}$ \\
\hline Department Name & Name of the functional department. \\
\hline Department Manager & Manager of the functional department. \\
\hline Department Strength & The numerical strength of the department \\
\hline Department Function & $\begin{array}{l}\text { Primary function of the department-design, manufacture, } \\
\text { production, inventory control, marketing etc. }\end{array}$ \\
\hline
\end{tabular}


Table 13: Attribute Table of the object 'Functional Department'

\begin{tabular}{|l|l|}
\hline \multicolumn{1}{|c|}{ Object Name } & \multicolumn{1}{c|}{ Customer } \\
\hline Definition & The customer or the client of putting in the ECR. \\
\hline \multicolumn{1}{|c|}{ Attribute Name } & \multicolumn{1}{c|}{ Definition } \\
\hline Customer_ID (PK) & $\begin{array}{l}\text { The unique identification number assigned to the customer. This } \\
\text { will be the primary key of the object-customer. }\end{array}$ \\
\hline EC Item & $\begin{array}{l}\text { The item for which the customer is requesting a change- } \\
\text { process,part,component,subcomponent,supplies,documentation } \\
\text { etc. }\end{array}$ \\
\hline $\begin{array}{l}\text { Customer } \\
\text { Specifications }\end{array}$ & The technical specifications as needed by the customer. \\
\hline
\end{tabular}

Table 14: List of Objects of 'Review an EC' Use Case

\begin{tabular}{|l|l|}
\hline \multicolumn{1}{|c|}{ Entity Name } & \multicolumn{1}{c|}{ Object Type } \\
\hline EC Review & Entity \\
\hline EC Quote & Entity \\
\hline EC board Member(s) & Entity \\
\hline EC Item & Entity \\
\hline EC Review Report & Entity \\
\hline
\end{tabular}

Table 15: Attribute table of the object 'EC Review'

\begin{tabular}{|l|l|}
\hline \multicolumn{1}{|c|}{ Object Name } & \multicolumn{1}{c|}{ EC Review } \\
\hline Definition & The review of an ECR done before approving or rejecting it. \\
\hline \multicolumn{1}{|c|}{ Attribute Name } & \multicolumn{1}{|c|}{ Definition } \\
\hline EC Review_ID (PK) & $\begin{array}{l}\text { The unique identification number assigned to any EC review. } \\
\text { This will be the primary key of the object- EC review. }\end{array}$ \\
\hline Review Date & $\begin{array}{l}\text { The date the review was conducted by the EC } \\
\text { board/committee. }\end{array}$ \\
\hline Review Type` & $\begin{array}{l}\text { The type of review conducted-design review, cost review, } \\
\text { scheduling review, manufacturing process review, materials } \\
\text { review, quality review. }\end{array}$ \\
\hline
\end{tabular}




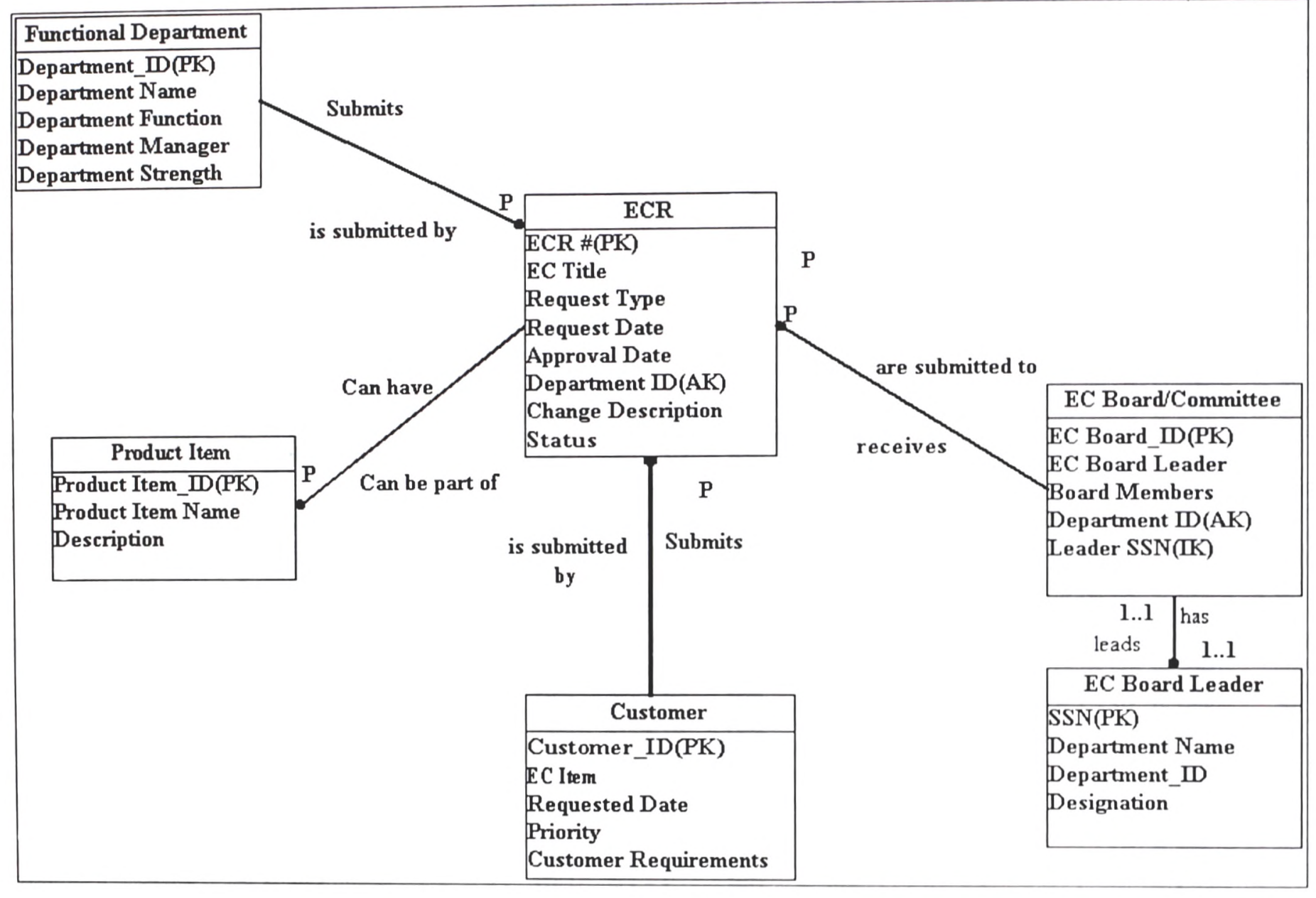

Figure 16: Object Class diagram of 'Request an EC' Use Case 
Table 16: Attribute table of the object 'EC Quote'

\begin{tabular}{|l|l|}
\hline \multicolumn{1}{|c|}{ Object Name } & \multicolumn{1}{|c|}{ EC Quote } \\
\hline Definition & $\begin{array}{l}\text { The quote/estimate given to a customer notifying the } \\
\text { customer about the cost incurred to execute the change. }\end{array}$ \\
\hline \multicolumn{1}{|c|}{ Attribute Name } & \multicolumn{1}{|c|}{ Definition } \\
\hline Quote_ID (PK) & $\begin{array}{l}\text { The unique identification number assigned to any EC quote. } \\
\text { This will be the primary key of the object- EC quote. }\end{array}$ \\
\hline Date Created & The date the EC quote was created. \\
\hline Estimated Delivery Date & The estimated completion date of the EC. \\
\hline EC Item Description & $\begin{array}{l}\text { The description of the item for which the EC quote is } \\
\text { requested. }\end{array}$ \\
\hline
\end{tabular}

Table 17: Attribute table of the object 'EC Item'

\begin{tabular}{|l|l|}
\hline \multicolumn{1}{|c|}{ Object Name } & \multicolumn{1}{c|}{ EC Item } \\
\hline Definition & $\begin{array}{l}\text { The EC item (product, part, component, subcomponent etc.) } \\
\text { for which the EC is requested. }\end{array}$ \\
\hline \multicolumn{1}{|c|}{ Attribute Name } & \multicolumn{1}{c|}{ Definition } \\
\hline EC Item_ID (PK) & $\begin{array}{l}\text { The unique identification number assigned to the EC item. } \\
\text { This will be the primary key of the object- EC Item. }\end{array}$ \\
\hline Product Item_ID(AK) & The product to which the EC Item belongs to. \\
\hline Product Item Name & $\begin{array}{l}\text { The name of the product item to which the EC item belongs } \\
\text { to }\end{array}$ \\
\hline EC Item Description & The description of the item for which the EC is requested. \\
\hline Change Type & Specifying the type of the EC \\
\hline Version & $\begin{array}{l}\text { The version of the EC item if it has previously undergone EC } \\
\text { in the past. }\end{array}$ \\
\hline
\end{tabular}

Table 18: Attribute table of the object 'EC Review Report'

\begin{tabular}{|l|l|}
\hline \multicolumn{1}{|c|}{ Object Name } & \multicolumn{1}{c|}{ EC Review Report } \\
\hline Definition & $\begin{array}{l}\text { The review report depicting the possible impacts on the } \\
\text { design, manufacturing processes, materials, lead-time, cost } \\
\text { and quality due to an EC. }\end{array}$ \\
\hline \multicolumn{1}{|c|}{ Attribute Name } & \multicolumn{1}{c|}{ Definition } \\
\hline Report_ID (PK) & $\begin{array}{l}\text { The unique identification number assigned to the EC review } \\
\text { report. }\end{array}$ \\
\hline EC Review_ID(AK) & The review that results in the creation of the report. \\
\hline Review Item & The description of the EC item that's being reviewed. \\
\hline Review Type & $\begin{array}{l}\text { States the type of review report: - design review, processes } \\
\text { review, cost review, scheduling review. }\end{array}$ \\
\hline
\end{tabular}




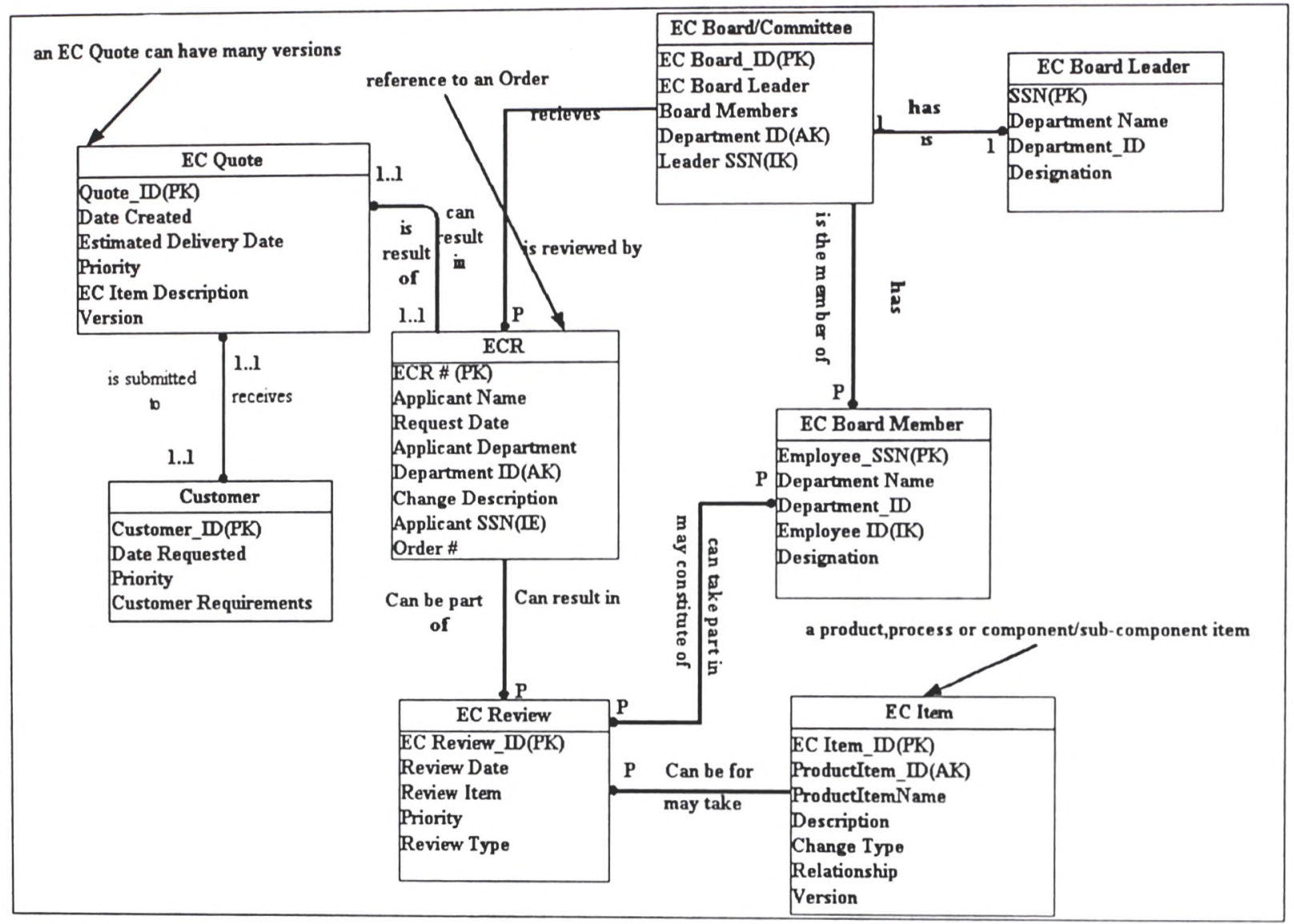

Figure 17: Object Class diagram of 'Review an EC' Use Case 
Table 19: List of objects of 'Order an EC' Use Case

\begin{tabular}{|l|l|}
\hline \multicolumn{1}{|c|}{ Entity name } & Object Type \\
\hline ECO & Entity \\
\hline ECO Form (Interface) & Interface \\
\hline Functional Departments & Entity \\
\hline EC board & Entity \\
\hline EC board leader & Entity \\
\hline
\end{tabular}

Table 20: Attribute table of the object 'ECO'

\begin{tabular}{|l|l|}
\hline \multicolumn{1}{|c|}{ Object Name } & \multicolumn{1}{c|}{ ECO } \\
\hline Definition & $\begin{array}{l}\text { An ECO is the official order issued to functional departments } \\
\text { to implement an EC in technical terms and with customer } \\
\text { specifications. }\end{array}$ \\
\hline \multicolumn{1}{|c|}{ Attribute Name } & \multicolumn{1}{c|}{ Definition } \\
\hline ECO_ID (PK) & $\begin{array}{l}\text { The unique identification number assigned to the ECO- } \\
\text { primary key. }\end{array}$ \\
\hline ECO name & The name of the ECO in technical terms. \\
\hline EC description & $\begin{array}{l}\text { The description of the EC in terms of customer requirements, } \\
\text { customer specifications, implementation details etc. }\end{array}$ \\
\hline Receiving Department(s) & $\begin{array}{l}\text { The functional department(s) responsible for executing the } \\
\text { change. }\end{array}$ \\
\hline Change Type & The type of EC. \\
\hline Start Date & The date when the EC should be started to be incorporated. \\
\hline End Date & The final delivery date of the EC with the expected result. \\
\hline
\end{tabular}

Object Class diagram for 'review an EC'

Figure 17 shows the object class diagram for the activity 'review an EC'. An ECR can be initiated for a particular order represented by the object attribute order \#. The order \# refers to a particular order for an EC. One ECR can result in one or one to many EC quotes given to the customer, defined by the attribute version \#. An ECR is also related to an EC item in the sense that one ECR can be initialized for one or one to many EC items. 
Table 21: Attribute table of the object 'Product Item'

\begin{tabular}{|l|l|}
\hline \multicolumn{1}{|c|}{ Object Name } & \multicolumn{1}{c|}{ Product Item } \\
\hline Definition & $\begin{array}{l}\text { The product, part, component, sub-component that has to } \\
\text { undergo the EC. }\end{array}$ \\
\hline \multicolumn{1}{|c|}{ Attribute Name } & \multicolumn{1}{c|}{ Definition } \\
\hline Product Item_ID (PK) & $\begin{array}{l}\text { The unique identification number assigned to the product } \\
\text { Item-primary key. }\end{array}$ \\
\hline EC Item_ID (AK) & The identification number for an EC item. \\
\hline Product Item Name & The name of the product/part/component/sub-component. \\
\hline Description & The description of the product item undergoing the change. \\
\hline Change Type & The type of EC. \\
\hline Version & $\begin{array}{l}\text { The version of the product item undergoing the change if at } \\
\text { all it has gone changes previously. }\end{array}$ \\
\hline
\end{tabular}

Object Class diagram for 'plan for EC'

Refer to Figure 18 for the object class diagram of 'plan for EC/create an ECO' Use Case. One engineering change item can have one or one to many product items. For example an ECR is requested for change in the specifications of a particular component (EC Item), which in turn consists of one or more sub-components (product items) then this ECR will address the need for change of all the constituting components and subcomponents. On the other hand a particular component/subcomponent during its manufacture must have been made of one and only engineering process. 


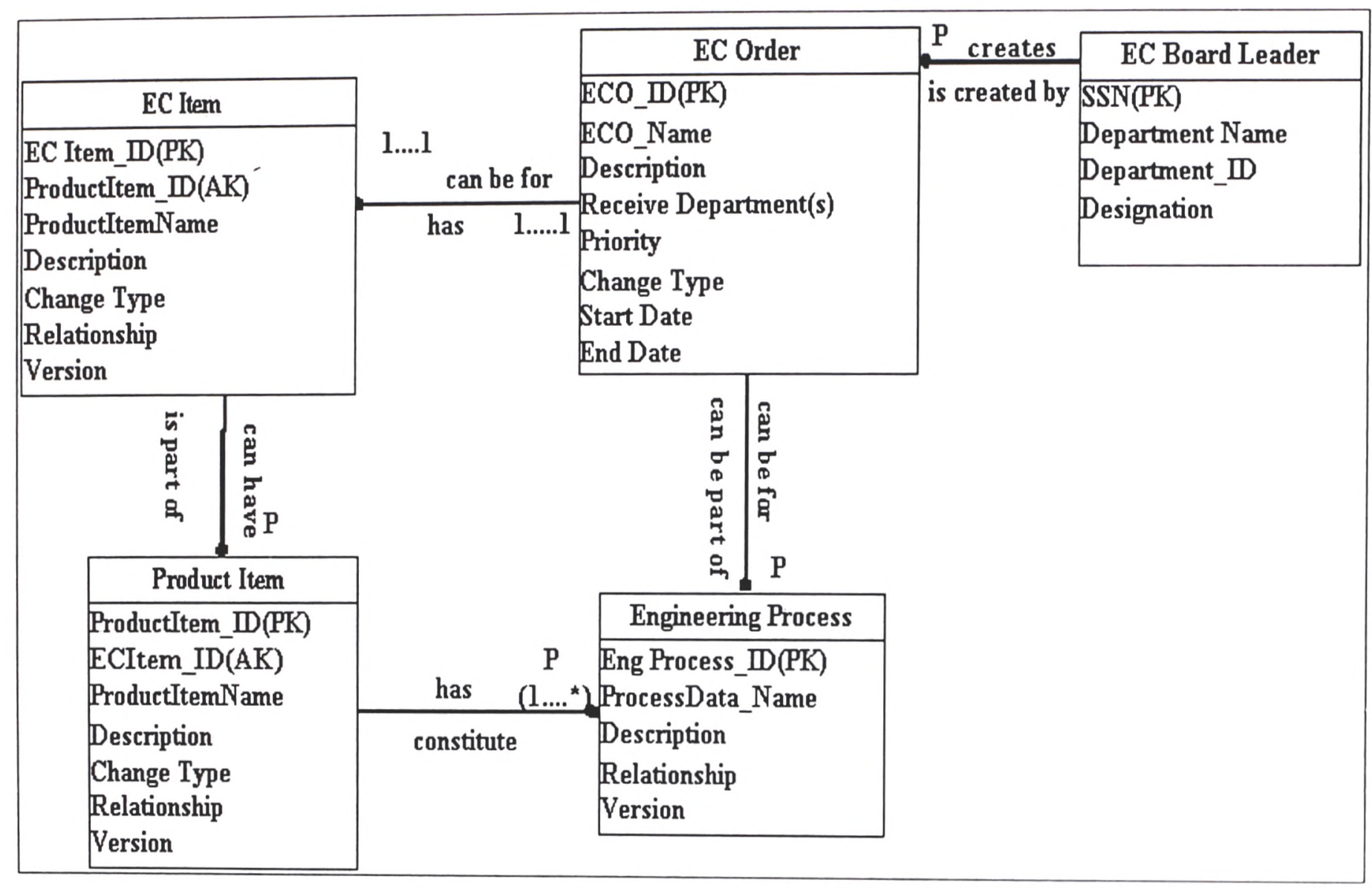

Figure 18: Object Class diagram of 'Plan for EC/Create an ECO' Use case 
Table 22: List of objects of 'Deploy an ECO' Use Case

\begin{tabular}{|l|l|}
\hline \multicolumn{1}{|c|}{ Entity Name } & Object Type \\
\hline ECN & Entity \\
\hline EC Progress Report & Entity \\
\hline EC Progress Report Interface & Interface \\
\hline
\end{tabular}

Table 23: Attribute table of the object 'ECN'

\begin{tabular}{|l|l|}
\hline \multicolumn{1}{|c|}{ Object Name } & \multicolumn{1}{|c|}{ ECN } \\
\hline Definition & $\begin{array}{l}\text { The notification issued by the functional department or } \\
\text { the EC project owner notifying all the concerned } \\
\text { departments and the EC board about the complete } \\
\text { implementation of the EC Project. }\end{array}$ \\
\hline \multicolumn{1}{|c|}{ Attribute Name } & \multicolumn{1}{|c|}{ Definition } \\
\hline ECN_ID (PK) & $\begin{array}{l}\text { The unique identification number assigned to ECN- } \\
\text { primary key. }\end{array}$ \\
\hline Part & The part for which the EC project was initiated. \\
\hline Process & Process for which the EC project was initiated. \\
\hline Description & $\begin{array}{l}\text { The description of the product/process item that } \\
\text { underwent the change. }\end{array}$ \\
\hline Process/Project Owner & $\begin{array}{l}\text { The person/functional department responsible for } \\
\text { executing the change. }\end{array}$ \\
\hline ECN version & $\begin{array}{l}\text { The version of the ECN undergoing the change if at all it } \\
\text { has been previously modified. }\end{array}$ \\
\hline Action Taken & $\begin{array}{l}\text { The implementation details to completely implement the } \\
\text { EC. }\end{array}$ \\
\hline Date Issued & The Date the ECN was issued. \\
\hline
\end{tabular}

Object Class diagram of 'execute engineering change'

After executing an EC the participating or the implementing functionality creates the ECN depicting the implementation details of the EC. The EC project/process owner, the part for which the change was executed and the date when the ECN was issued are one of the most critical attributes that define them. 


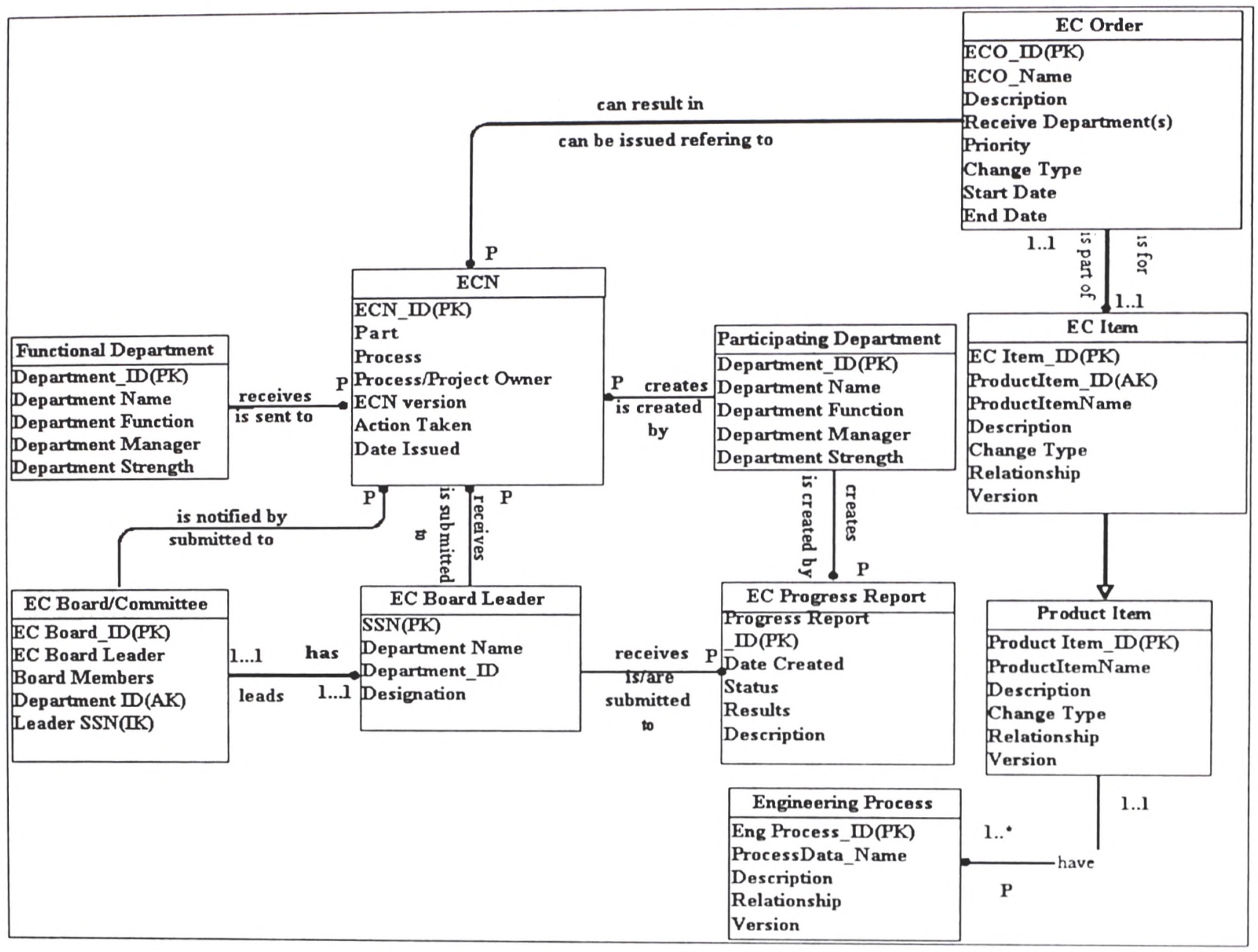

Figure 19: Object Class diagram of 'Execute the EC' Use case 
Table 24: List of objects of 'Conduct Post-Implementation Assessment' Use Case

\begin{tabular}{|l|l|}
\hline \multicolumn{1}{|c|}{ Behavior/Entity name } & \multicolumn{1}{c|}{ Object Type } \\
\hline EC Result Report & Entity \\
\hline EC Result Report Interface & Interface \\
\hline $\begin{array}{l}\text { Post-Implementation } \\
\text { Assessment }\end{array}$ & Entity \\
\hline EC Result Report & Entity \\
\hline
\end{tabular}

The object class diagrams of all the use cases mentioned above are put together to create the object class model for ECM. The complete object class model of ECM is shown in Appendix D. Thus the object model is based on all the data entities already identified by the activity model right from the activities constituting the EC process to the objects involved in those activities. Shown below are the cardinality conventions followed for the object class model of ECM and the individual object class diagrams.

Table 25: Symbols and Cardinalities for 'Object class model for ECM'

\begin{tabular}{|l|l|l|}
\hline \multicolumn{2}{|c|}{ Symbol } & \multicolumn{1}{c|}{ Object Type } \\
\hline \multicolumn{1}{|c|}{$\begin{array}{c}\text { ObjectName } \\
\text { Attributes }\end{array}$} & Entity \\
\hline \multicolumn{2}{|c|}{ Cardinality Notations } \\
\hline & P & One-to-one or many \\
\hline & $\mathbf{N}$ & One-to-exactly N \\
\hline & Where N $=1 \ldots . \mathrm{n}$ \\
\hline
\end{tabular}




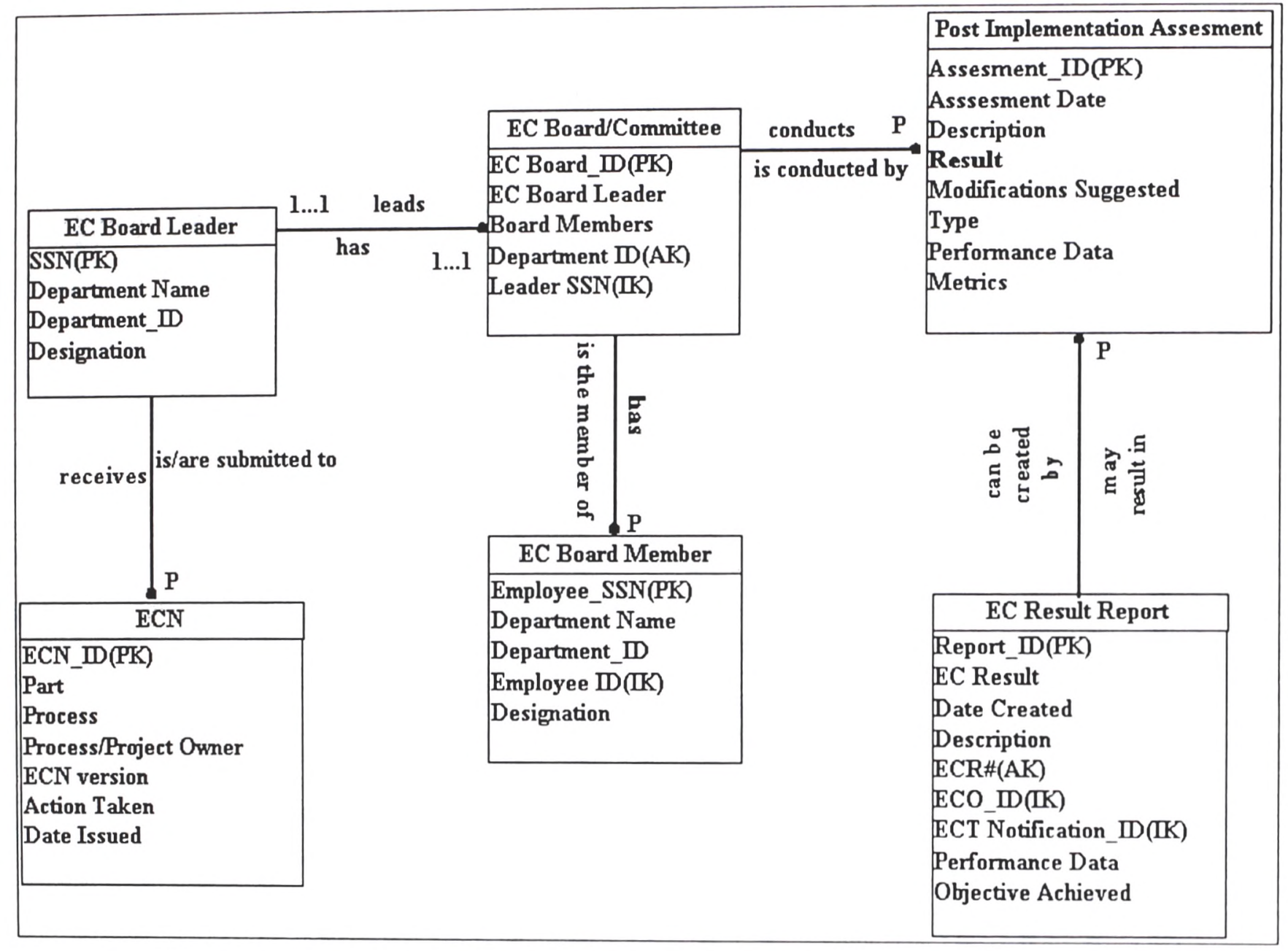

Figure 20: Object Class diagram of 'ECN' 


\subsection{Dynamic Modeling}

Object class modeling examines the static structure of the ECM system by just identifying the structure and the relationships (cardinalities) of the engineering change process objects. However, dynamic modeling addresses the dynamic behavior of objects identified in the object model (refer Appendix D) via the different events that take place while executing an EC right from 'request an EC' to 'Post-Implementation Assessment', and associated state changes that can happen to an object during different execution states.

\subsubsection{Framework for the Dynamic Model}

Please refer to the framework for the dynamic model in Appendix E. Every object and actor in the framework of the dynamic model is accompanied by its symbol. The leftmost column shows the activity flow of all the business activities for executing an EC. The process starts with an ECR put forth by customer(s) (Actor1) and any functional department (Actor 2) after identifying it. Both the actors mentioned above are also objects and in addition to this there is also the ECR which can be identified as an object. The status of the object ECR can be identified as submitted, reviewed and approved/rejected. Customer requirements, EC result, engineering requirements and order specifications are the inputs to the object ECR. The second activity will be the 'EC review' also 'will be carried out by the actors as shown in the framework. The EC review is also an entity object and goes through the following states of manufacturing process review, materials review, quality review, scheduling review and cost review. Please refer to the inputs and the outputs to every object which are a part of the EC review. The next logical activities of creating an ECO, routing the ECO to functional departments, are also 
identified with its objects, actors, inputs and outputs. Implementing the EC is characterized by the following objects: - functional departments, ECN and EC progress report. Please refer to the comments column to check the functionality of every object and its output.

\subsubsection{State Diagrams}

State Diagrams are drawn for objects to depict the status of the objects during their life cycle right from their birth to their termination. Different events take place to trigger a change in the state of a particular object. A state diagram that links states through events describes the behavior of a single class of objects. Each event corresponds to the method of the object. This research has captured the dynamics of critical objects in the engineering change process from the activity model and translated them to state diagrams. Figure 21 shows the different states through which the object ECR goes through during its life cycle right from its creation by the customer or by a functional department. Figure 22 shows the object life cycles of the object ECO. Figure 23 shows the object life cycle of the object ECN and Figure 24 shows the object life cycle of 'EC review'. 


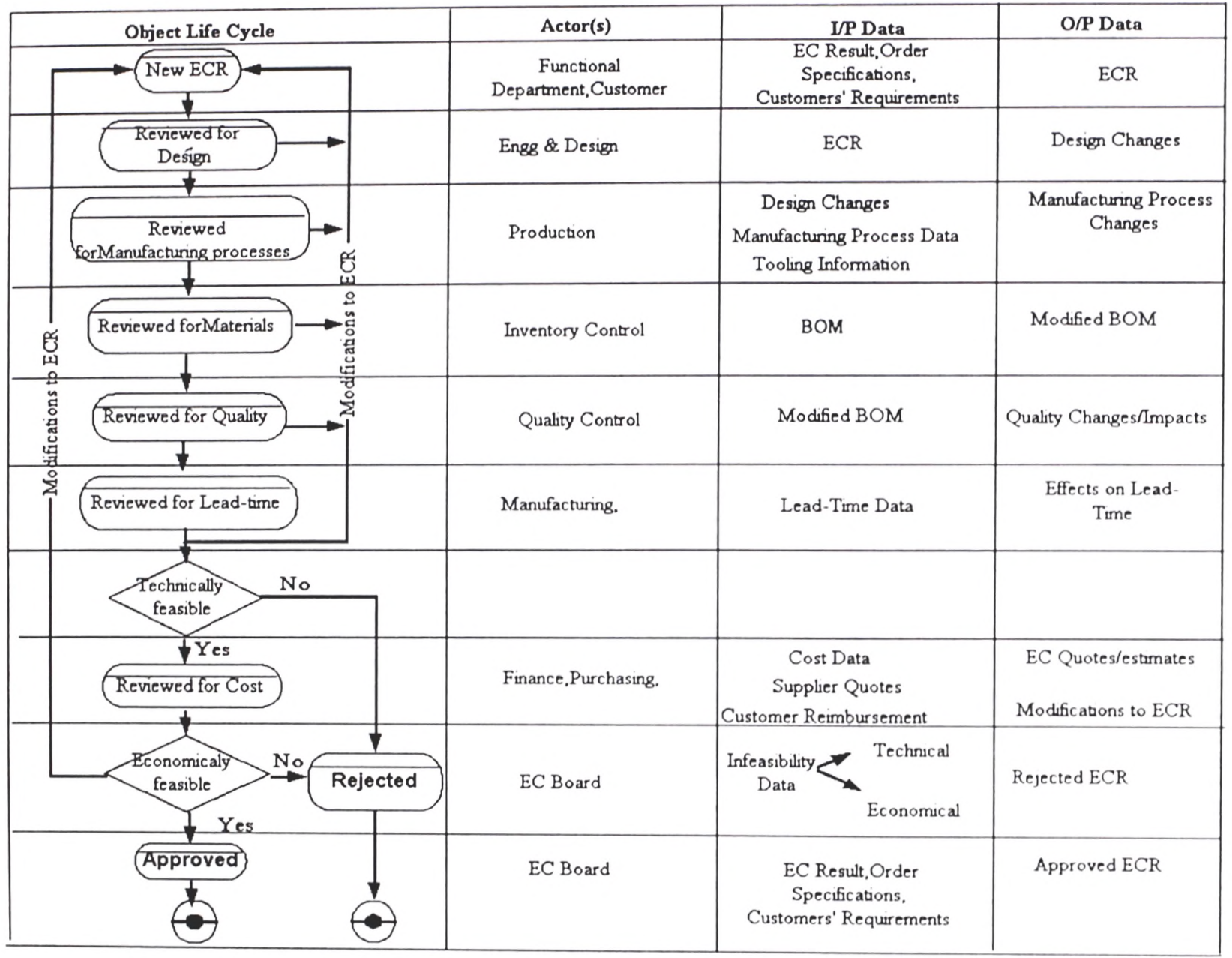

Figure 21: Object life cycle of 'ECR' 


\begin{tabular}{||c|c|c|c|c|}
\hline Object Life Cycle & Actor & Trigger & I/P Data & O/P Data \\
\hline New ECO & $\begin{array}{c}\text { EC Board } \\
\text { Project / Process Owner }\end{array}$ & $\begin{array}{c}\text { Approval of } \\
\text { ECR }\end{array}$ & Customer Specifications & $\begin{array}{c}\text { ECO Document with } \\
\text { implementation Details }\end{array}$ \\
\hline $\begin{array}{c}\text { Planned } \\
\text { Scheduled }\end{array}$ & Project / Process Owner & Approval of & $\begin{array}{c}\text { ECR } \\
\text { Product Platform and } \\
\text { architecture } \\
\text { manufacturing process } \\
\text { information } \\
\text { Pert /Cantt charts }\end{array}$ & $\begin{array}{c}\text { Allocated Resources } \\
\text { Approval Information } \\
\text { Product-Processchange } \\
\text { matrix } \\
\text { BOM }\end{array}$ \\
Released & Functem level design change \\
Implemented & $\begin{array}{c}\text { Froject Owner } \\
\text { allied entities }\end{array}$ & $\begin{array}{c}\text { Approved } \\
\text { ECO }\end{array}$ & Implementation Details & ECN \\
\hline
\end{tabular}

Figure 22: Object life cycle of object 'ECO' 


\begin{tabular}{|c|c|c|c|c|}
\hline Object Life Cycle & Actor & Trigger & I/P Data & O/P Data \\
\hline New ECN & Functional Dept. & $\begin{array}{c}\text { Implemented } \\
\text { EC }\end{array}$ & $\begin{array}{c}\text { Changed Specifications. } \\
\text { Implementation Details }\end{array}$ & $\begin{array}{c}\text { EC Result } \\
\text { EC progress Report }\end{array}$ \\
\hline Reviewed & $\begin{array}{c}\text { EC Board, } \\
\text { Functional } \\
\text { Departments }\end{array}$ & Created ECN & $\begin{array}{c}\text { Performance Data } \\
\text { Changed Specs. }\end{array}$ & Modifications \\
\hline Ep Board & Eeviewed & $\begin{array}{c}\text { EC Goals\& } \\
\text { Objectives }\end{array}$ & EC Result Report \\
\hline
\end{tabular}

Figure 23: Object life cycle of object 'ECN' 


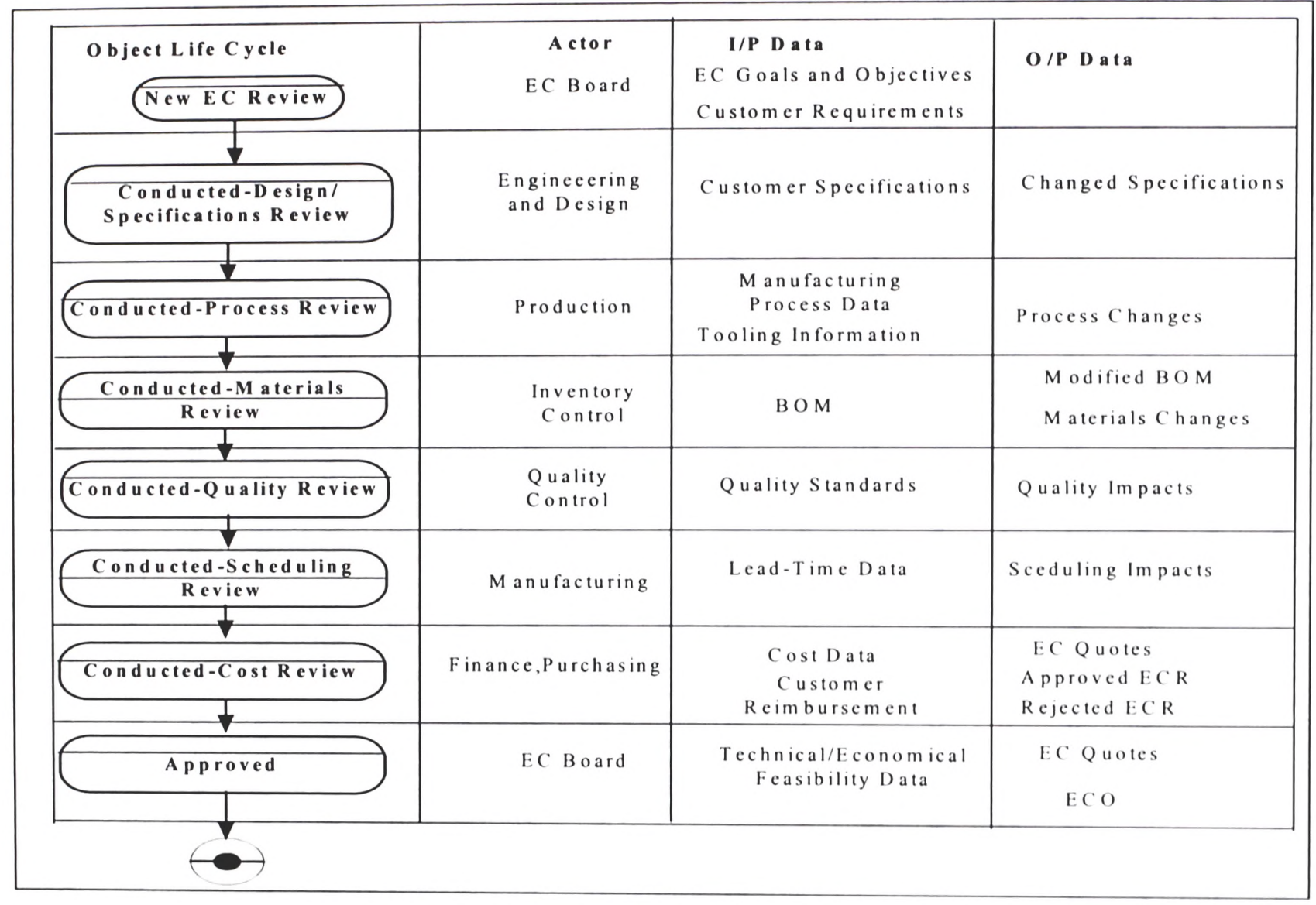

Figure 24: Object life cycle of the object 'EC Review' 


\subsubsection{Sequence Diagrams}

Sequence Diagrams are used to depict the interaction between various objects in terms of events/activities that relate them. In other words they represent detailed activities depicting the role of the objects in those activities. Please refer to Appendix A for the sequence diagram of 'Request an EC'. The actor initiating the event, that is a customer or any functional department requesting the $\mathrm{EC}$, logs in with user name and password using the form to check-in as part of the ECMS. At the back end the log-in information is verified, which logs the user in. The actor selects the option of 'Make an ECR Proposal' from the options form of ECMS. The form is displayed. The actor fills in all the relevant information for the new ECR, namely customers requirements, the expected EC result, the engineering requirements and order specifications. This EC related data is saved in the EC database under a unique ECR proposal number.

Appendix A shows the sequence diagram of 'EC review and EC execution'. The actor in this sequence of events is the EC board leader. After logging in with the user name and password the actor selects the 'EC review and ordering'. The EC board leader will select the particular ECR for which the EC board leader wants to view the EC review report. After the system displays the contents of the ECR the EC board leader selects the option to view 'Review Reports' prepared by the respective departments. Also please observe the back-end operations of the EC repository. The EC board leader depending on the view of the EC committee approves the ECR and inputs the approbation command. The approbation result is saved in the EC repository. The system in response to this creates the ECO with all the technical details and implementation details attached to it. The EC board leader then routes the ECO to the related disciplines or departments to be 
implemented with the implementation details. The routing information along with all the relevant $\mathrm{EC}$ details is saved in the EC repository.

Appendix A shows the sequence diagram of 'EC Review Report' and 'EC Progress Report' creation. The functional department head (user) or the person responsible for preparing these reports will log-in. The user will the select the option of create an 'EC Review Report' fill in the data of the type of the review conducted and would save the details of the EC review. The routing information will be used to route the EC review report to the concerned departments and the EC board as part of the EC review.

\subsection{SUMMARY}

The development process starts with the PD process which we believe is the foundation for the EC process. The triggers to engineering changes are shown as different types of changes at the various product development stages. Then the overall development of the model is explained with the functional requirements of an engineering change process is mentioned. The development of the model starts with the mapping of the basic activities of the engineering change process starting with requesting an engineering change, reviewing the engineering change, planning for the change and executing it. The modeling starts with use case modeling where all the use cases pertaining to these activities are enumerated. These use cases are then used to develop the activity models where IDEF0 diagrams have been used to depict every activity in its functional form. Thus the final IDEF0 model ECM shown in Figure 11 has achieved the objective of capturing the EC process and the EC data in its functional form. The criterion of dividing the business process into its hierarchical activities and sub-activities 
was satisfied. All the data entities from the object model are identified and then defined in terms of their attributes (Table 7 through Table 24). Simultaneously object class diagrams are drawn for every activity of the activity model and the cardinalities are identified. Thus this chapter culminates with the completely developed object class model for engineering change management. Dynamic modeling starts by depicting state diagrams for the following objects: - ECR, ECO, ECN and EC review. The state diagrams depict the object life cycle right from its birth till the culmination of the object life. The actors responsible for the change in the state of these objects are also identified along with the input data, output data that trigger the event causing a change in the state of the object. Sequence diagrams are used to show the interaction between objects and the events that trigger them. Appendix A shows all the sequence diagrams. 


\section{CHAPTER}

\section{VALIDATION}

The information model developed in this research is validated in terms of its objectives that were achieved. The results of this research are compared against the objectives of this research. The prime objective of this research was to capture the EC process flow and data to guide the execution of EC. Use case modeling was used to develop an activity model. The activity model mapped the whole business process of managing engineering changes right from 'making an ECR', reviewing the ECR, plan for ECO and to execute the EC. Every activity and sub-activity which is an inherent part of the process of EC was identified along with the inputs that go into that activity, the outputs of the activity/sub-activity, the controls within which the activity has to be executed and the mechanism.

Another objective of this research was to capture the EC data. Data flow to every activity was identified in the activity model. The object class model was developed form the activity model wherein critical objects were identified and were defined in terms of their attributes. Tracking of these critical objects is facilitated by the object class model and the dynamic model for the users of an ECM system. Another objective of this research was to capture the life cycle of objects critical in the EC process. Defining the inter-relationships amongst these objects was also an important parameter. This was achieved by the dynamic model depicting the life cycles of critical objects namely: ECO, ECN and ECR. It also identified the actors who trigger a change in the state of the objects and the input data which trigger these changes in state. The cardinalities between these objects showed the interdependencies amongst these objects. 
The other important objective of this research was to achieve process integration in managing ECs. Process integration was achieved by the activity model which streamlines all the constituting activities of managing ECs and the information related to these changes. 


\section{CHAPTER}

\section{CONCLUSION}

This chapter concludes this research in two sections. The section 5.1 summarizes the development work of the research and section 5.2 discusses about the future work. The literature review has shown that although much attention has been given to the procedural management and administrational issues of engineering changes, there has been no work contributed to capture the essence of engineering change management in its true sense. There has never been a generic model proposed to guide the execution of engineering changes in terms of activities, entities (objects) and the states of these critical objects.

\subsection{SUMMARY}

This research focused on the development of an information model for managing EC. This goal was achieved by developing a model based on standardized modeling techniques like IDEF0 and IDEF1X, to develop 'activity model' and 'object model'. This work was successful in providing a generic information model which focused on the business process of executing an EC in terms of its constituting hierarchical activities and sub-activities. Inputs to every function (activity), outputs of every function and the mechanisms that stand for resources to perform those activities (functions) were also identified. The object model identified all the objects in the EC process that are part of the activity model and defined them in terms of the objects' attributes. The cardinality of the objects shows the relationships these objects have with each other. The dynamic model captured the object life cycle of the objects in an EC process. The dynamic model also captured the status change of critical objects and the actor (who does it). The 
dynamic model also identified the input and the output data responsible for triggering the event that brings the change in the state of the object. This information model captures all functional participants of an engineering change process along with the information flow related to each one of them. Therefore it can also be said to be a generic model that can serve as an appropriate platform for developing an enterprise system for engineering change management.

\subsection{FUTURE WORK}

The future work addresses the issue of refining the model to make it adaptable to a collaborative environment. The very basic approach of this research was to bring and align the engineering change process as close as possible to the product development process. A generic model was developed for the engineering change process of a manufacturing company.

\subsubsection{Refinement of the Information model}

There are a few aspects which could be considered for refining the information model. The next logical questions that arise are:-Can the present model be refined so as to handle engineering changes when the product development involves multiple manufacturing organizations? Can this model be used in a collaborative environment? If yes, how different will the informational model be for such a scenario? How will the business process of executing an engineering change in such a multi-company setting vary? Will the engineering change information flow as identified in the activity model of this research be any different? Will the dynamics of such an information model be the same? The answers to these questions can be used to polish the information model developed in this research. 


\subsubsection{Proposed System Architecture}

The other obvious and logical concern would be to propose a system architecture using the features of the information model developed. The whole architecture can be composed of three parts, refer Figure 25.

The Central Project Database: - The heart of the model as shown in Figure 25 is a 'Central Project Database'. The project database can consist of three parts 'EC database', 'Product design database' and 'Product components database'. The product components database functions as a repository for all the design data that are necessary to describe every product component in an EC project. This will include all the units which make up the product. The product design database acts a repository for all the design information of the product, i.e. the product architecture. It will describe the major units and the functional parts of the product. The EC database is a repository of all the ECs executed till date and all the relevant information corresponding to it and documentation, design information and also information required for managing the various functions of the information model. There will be two sub-systems of the architecture the EC manager system (for the EC Team) and the EC Execution system (functional participants). The whole system is a modularized system wherein every module which will be a part of either the EC manager system or the EC Execution system will be linked to the central database through SQL.

EC Manager System: - The EC board leader who is responsible for the overall execution of the EC is linked to the central project database through a group of modules called the 'EC manager system'. The EC manager system will also be linked to a general 
database of the organization. The EC manager system will consist of the EC Ordering module, EC tracking module, EC mapping module and the EC review module.

EC ordering module will address the functionality of EC ordering. The EC board leader orders an EC through the EC ordering module. This module will create an Engineering Change Order (ECO). After the EC team review, when the engineering change order has to be created to meet the goals and objectives of the EC, the EC team leader will create an ECO by specifying the departments to whom the ECO should go to and then submit it to the system.

EC review module will address the functionality of EC review. This module will be able to capture all the decisions made by the EC board as a result of the EC review and the post-implementation Review.

EC mapping module will address the functionality of EC routing. The functionality of EC mapping module for instance can be routing ECOs and ECNs (activity A4- in the activity model) to the respective departments responsible for deploying the EC.

EC tracking module will address the functionality of EC tracking. This module will be able to track the progress of every EC that is undertaken by the concerned departments/disciplines. The EC board leader will be able to query the status of any EC that is carried out. 


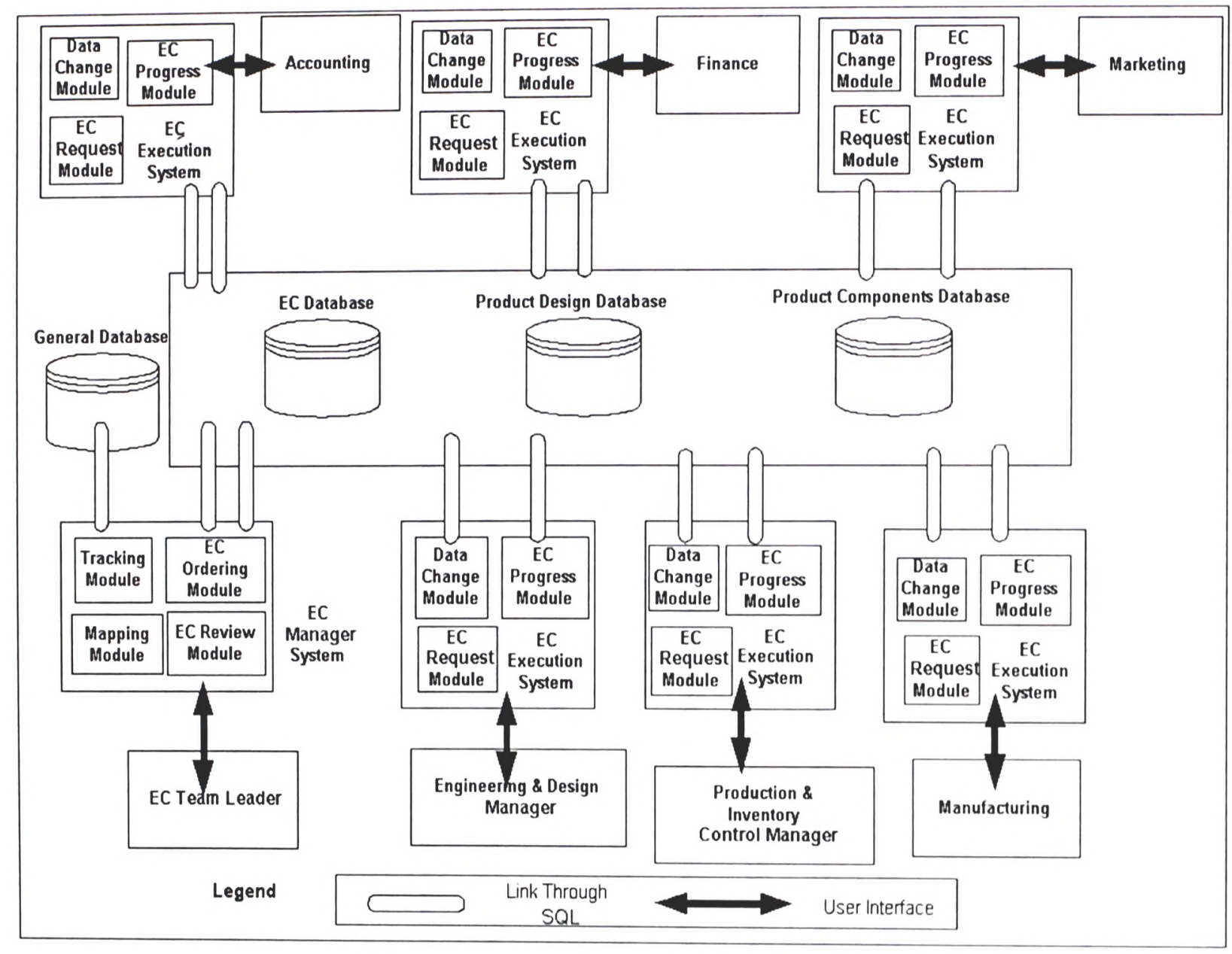

Figure 25: Overview of the Proposed System Architecture 
EC Execution System: - This system will be used by those contributing disciplines who will be responsible for deploying the EC and the once who could put forth the $\mathrm{EC}$ request for executing the $\mathrm{EC}$ to the $\mathrm{EC}$ team. The $\mathrm{EC}$ execution system can be spread over the following departments, since these are the functions that play a vital role in executing any EC in most of the organizations (Diprima, 1983):- Engineering and Design, Production and Inventory Control, Manufacturing, Marketing, Finance \& Accounting.

EC request module will address the functionality of EC requesting. Customers and functional department heads from the various departments through this module can submit a new ECR to the EC board. EC data change module will address the functionality of EC Implementation. Functional departments can change/modify the data of the product or any EC data pertaining to any EC through this module. EC progress module will address the functionality of EC progress tracking. Through this module the EC participants could prepare EC progress reports to be submitted to the EC board and related functionalities. Thus the implementation of the above architecture can be said to be an extension of the research.

\subsubsection{Implementation Issues}

This information model can be used as a basis to implement and develop an Enterprise System for Engineering Change Management. The following section describes the requirements for implementation in an engineering environment:-

Manage the EC data pertaining to the product (product structure, components etc.) in a collaborative environment. 
$>$ Link different computers available in different functional departments in order to facilitate processing of ECs.

$>$ A centralized system of data whereby all the relevant EC information can be stored thereby supporting collaborative ECM activities.

$>$ Provide access security to authorized persons. As these people can be internalEC board members, functional department heads or external-customers, suppliers etc.

$>$ Provide a notification service to report requesting, authorizing, approving, releasing and completing ECM activities.

$>$ The system should be based on database programming. The system should be based on object-oriented databases.

$>$ The computer aided system should be based on the client/server architecture.

$>$ The EC system should be modularly built-wherein one module specializes in one set of related functions- ordering EC, approving/authorizing EC, routing EC and reviewing EC.

$>$ To support interoperability in a heterogeneous environment, the system can be implemented based on the concept of CORBA (Common Object Request Broker Architecture).

$>$ Future work should be carried out to design the system and implement it in a three-tier layered architecture based on the technology of distributed objects and CORBA.

$>$ The first logical step would be to develop a prototype engineering change management system in a virtual engineering environment. 


\section{REFERENCES}

Balcerak K J and Dale B G (1992), "Engineering Change Administration: The Key Issues" Computer-Integrated Manufacturing Systems, Vol. 5, No. 2, 125-132.

Boznak R G (1993) Competitive Product Development, Milwaukee, WI: Business One Irwin/Quality Press.

Baruch I S, David M B and Sohoni V S (February 1993), "Avoiding Engineering Changes through Focused Manufacturing Knowledge", IEEE Transactions on Engineering Management, Vol. 40, No. 1, 54-58.

Chen Y M, Shir W S and Shen C-Y (2002), "Distributed Engineering Change Management for Allied Concurrent Engineering", International Journal for Computer Integrated Manufacturing, Vol.15, No. 2,127-151.

Choi F.C, Chan L "Business Process Reengineering: Evocation, Elucidation and Exploration", Business Process Management Journal, Vol. 3, 39-63.

Diprima M R (1982), "Engineering Change Control and Implementation Considerations" Production and Inventory Management, Vol. 23, No. 1, 81-87.

Diprima M R (1991), "Engineering Change Management for Long-Lead-Time Production Environments" Production and Inventory Management Journal, 84-88.

DEC, Fujitsu, IBM, Matrix One, Metaphase, SDRC, Sherpa, PDM enablers "Joint proposal to the OMG manufacturing domain task force RFP1",mfg/98-01-01.

Huge E C (1977), "Engineering Change Control: NCR Corporation", Proceedings of the 1977 APICS conference, 81-93.

Galati U K (1980), "Hidden Culprit in the Inventory Heap", Proceedings of the $23^{\text {rd }}$ APICS Conference, 279-282.

Hayes C C. and Sun H C. (1995), "Using a Manufacturing Constraint Network to Identify Cost Critical Areas of Design", Artificial Intelligence for Engineering Design, Analysis and Manufacturing, Vol. 9, 73-87.

Hedge G G, Kekre S (1989), "Engineering Changes and Time Delays: a field investigation, International Journal of Production Economics, Vol. 28, No. 8, 25-27.

Huang G Q and Mak K L (June 1997c) "Computer aids for Engineering Change Management", Proceedings of International Conference on Computer Aided Production Engineering, Poland. 
Huang G Q and Mak K L (1998), "Computer Aids for Engineering Change Control", Journal of Materials Processing Technology, Vol. 76, 19-187.

Huang G Q, Mak K L and Yee W Y (JULY 17-20, 1998), "Reengineering the Engineering Change Management Process", Seventh international ISPE international Conference on Concurrent Engineering, 255-264.

Huang G Q and Mak K L (1998), "Engineering Change Management: A survey within UK Manufacturing Industries", submitted to International Journal of Production and Operations management.

Huang G. Q. and K.L.Mak (1999), "Current practices of Engineering change management in UK manufacturing companies", International Journal of Operations and Production Management, Vol.19, No.1, 21-37.

Huang G Q, Mak K L, Lee W Y (June 2000), "Development of a web-based system for engineering change management", Robotics and Computer Integrated Manufacturing, Vol. 17, 225-267.

Kidd M W, Thompson (2000), "Engineering Design Change Management”, Integrated Manufacturing Systems, Vol. 11, No. 1, 74-77.

Krishnamurthy K, Law K H (1995), "Change management for Collaborative Engineering", Computing in Civil Engineering, Vol. 2, 1110-1117.

Maull R, Hughes D, Bennett J. (March 1992) "The Role of the Bill-of-Materials as a $\mathrm{CAD} / \mathrm{CAPM}$ Interface and the key Importance of Engineering Change Control", Computing \& Control Engineering Journal, 63-70.

McIntosh K G (1995), "Engineering Data management: A Guide to successful Implementation”, (New York: McGraw-Hill).

Mokhtar A, Bedard C and Paul F (April 1998), "Information Model for Managing Design Changes in a Collaborative Environment", Journal of Computing in Civil Engineering, Vol. 12, No. 2, ISSN 0887-3801/98/0002-0082-0092,82-91.

Nichols K'(1990), "Getting Engineering Changes under Control”, Journal of Engineering Design, Vol. 1, No. 1, 1-6.

Peter P and Malmquist J (1997), "A Comparative Study of Engineering Change Management in Three Swedish Companies", Machine and Vehicle Design, 1-11, Chalmers University of Technology.

Reidelbach P E (1991), "Engineering change management for long-lead-time environments" Production and Inventory Management Journal, Vol. 32 No. 2, 84-88. 
Rouibah K \& Caskey K R (2003), "Change management in concurrent engineering from a Parametric perspective", Computers in Industry, Vol. 50, 15-34.

Souder W. E, R K Moenart, A Meyer, D. Deschoolmaster (1994) - "Marketing integration mechanisms, communication and flows and innovation success", Journal of Product Innovation Management, Vol.11, 31-45.

Terwiesch C and Loch C H (1999), "Managing the Process of Engineering Change Orders: Case study of the climate control system in automobile development", Journal of product Innovation Management, Vol.16, 160-172.

Ulrich Karl T, Eppinger S D (2000), "Product Design and Development", $2^{\text {nd }}$ edition, ISBN 0-07-229647-X.

U.S Air Force ICAM Manual "IDEF0", The IDEF Source ${ }^{\mathrm{TM}}$, Wisdom Systems, Inc.

Wright I C (January 1997), "Engineering Changes: A case Study", production and Inventory Management Journal, Vol.25, 55-62.

Wright I C (January 1997), "A Review of Research into Engineering Change Management: Implication for Product Design”, Design studies, Vol.18, 34-42. 


\section{APPENDICES}

\section{APPENDIX A}

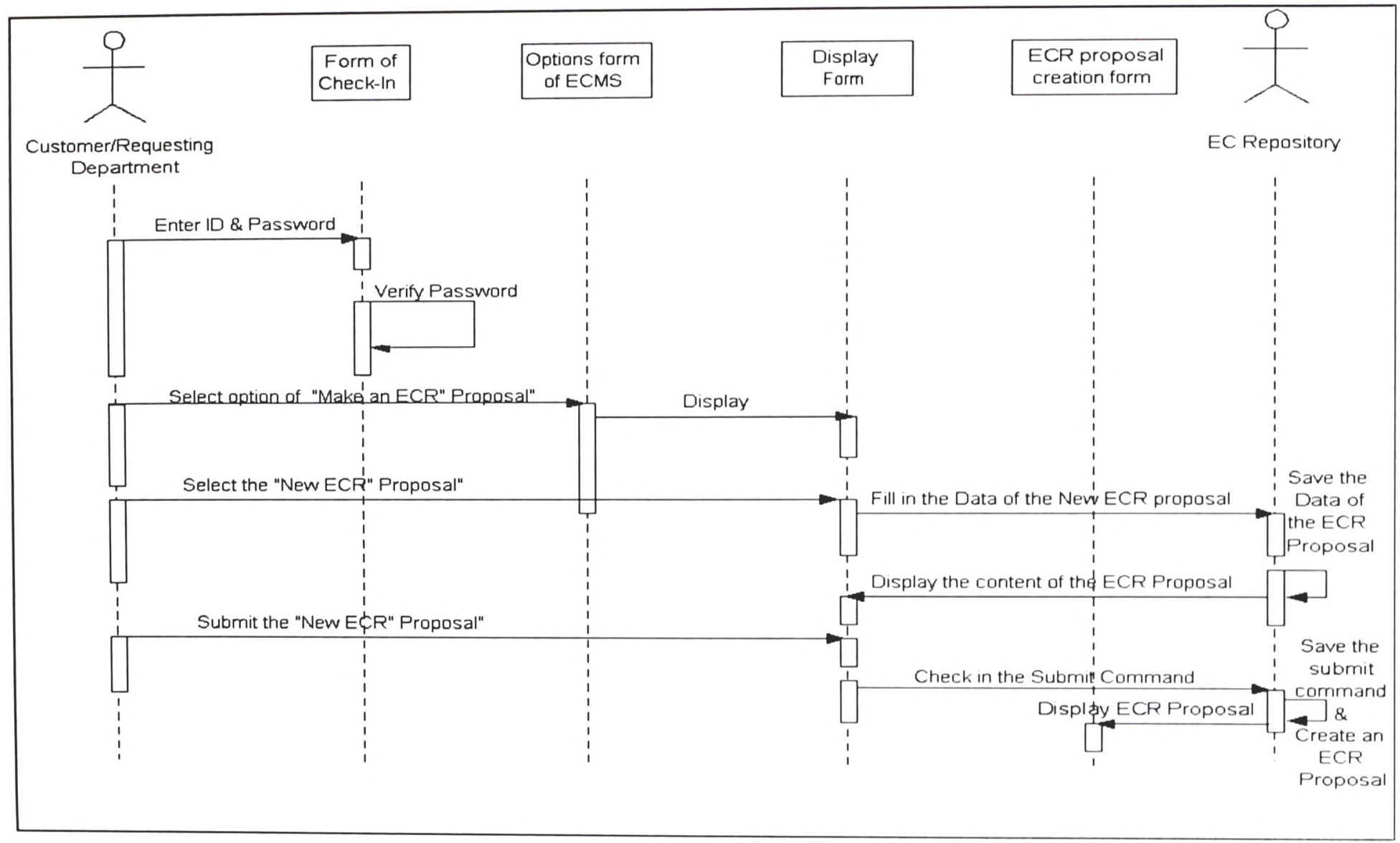




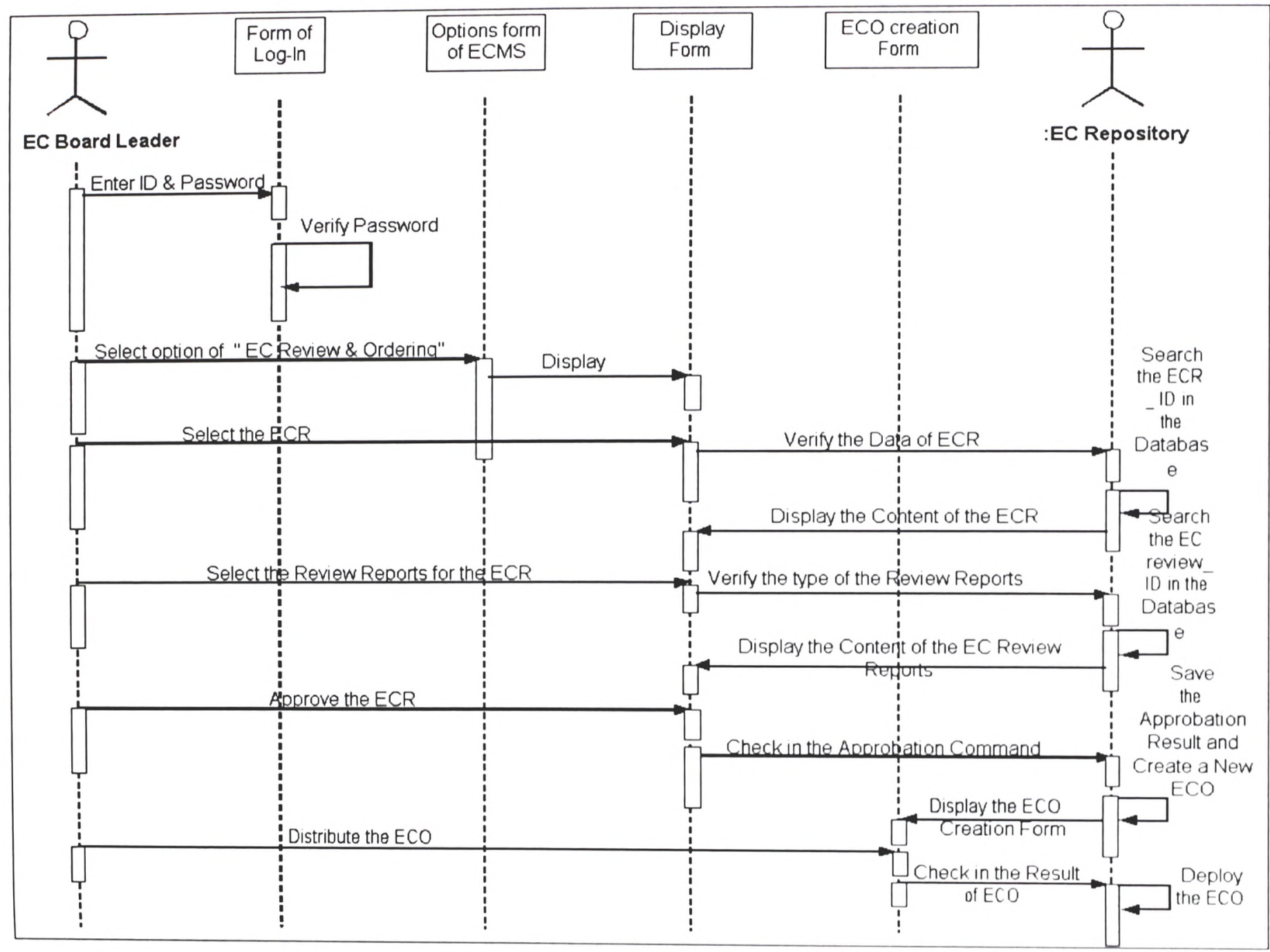




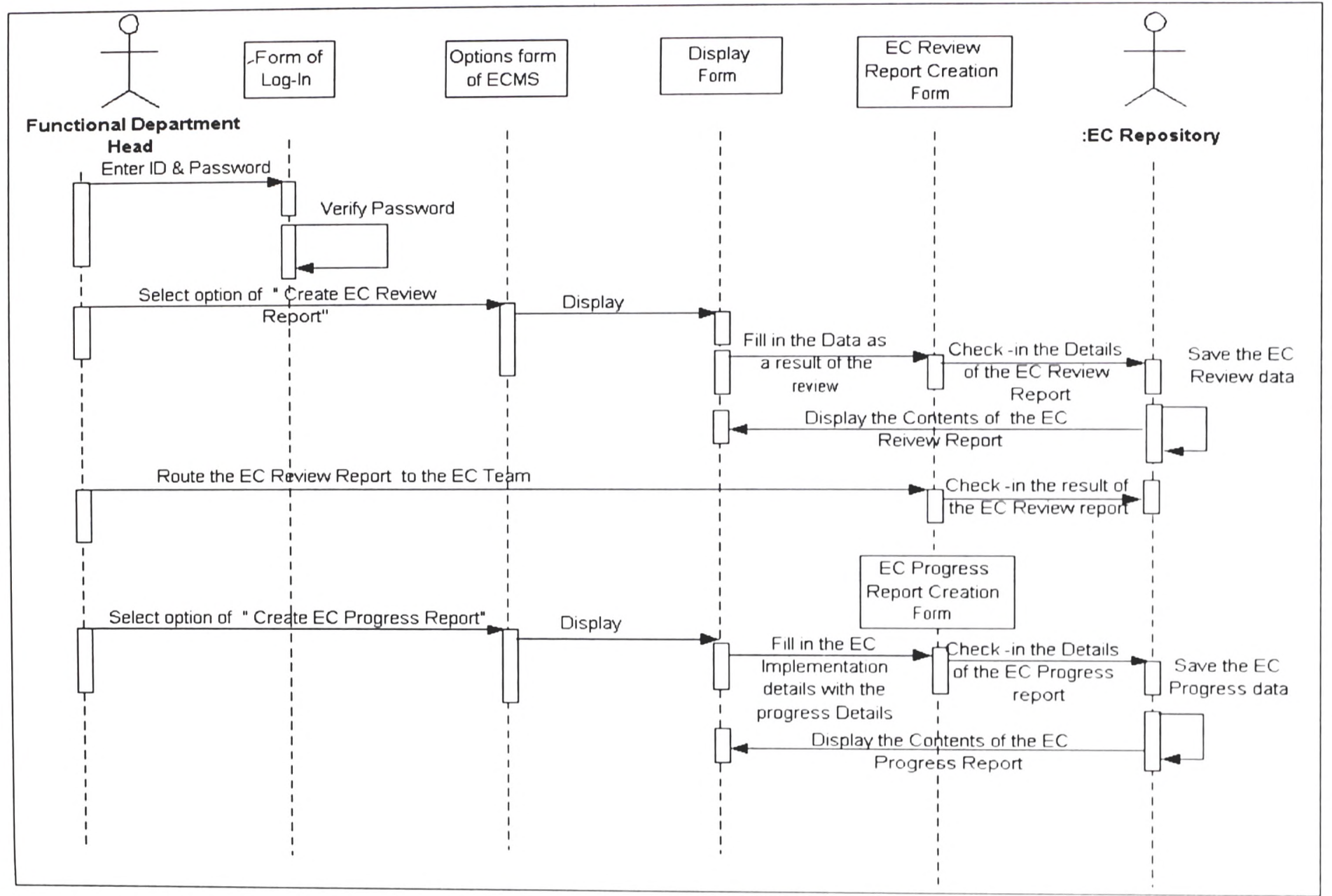




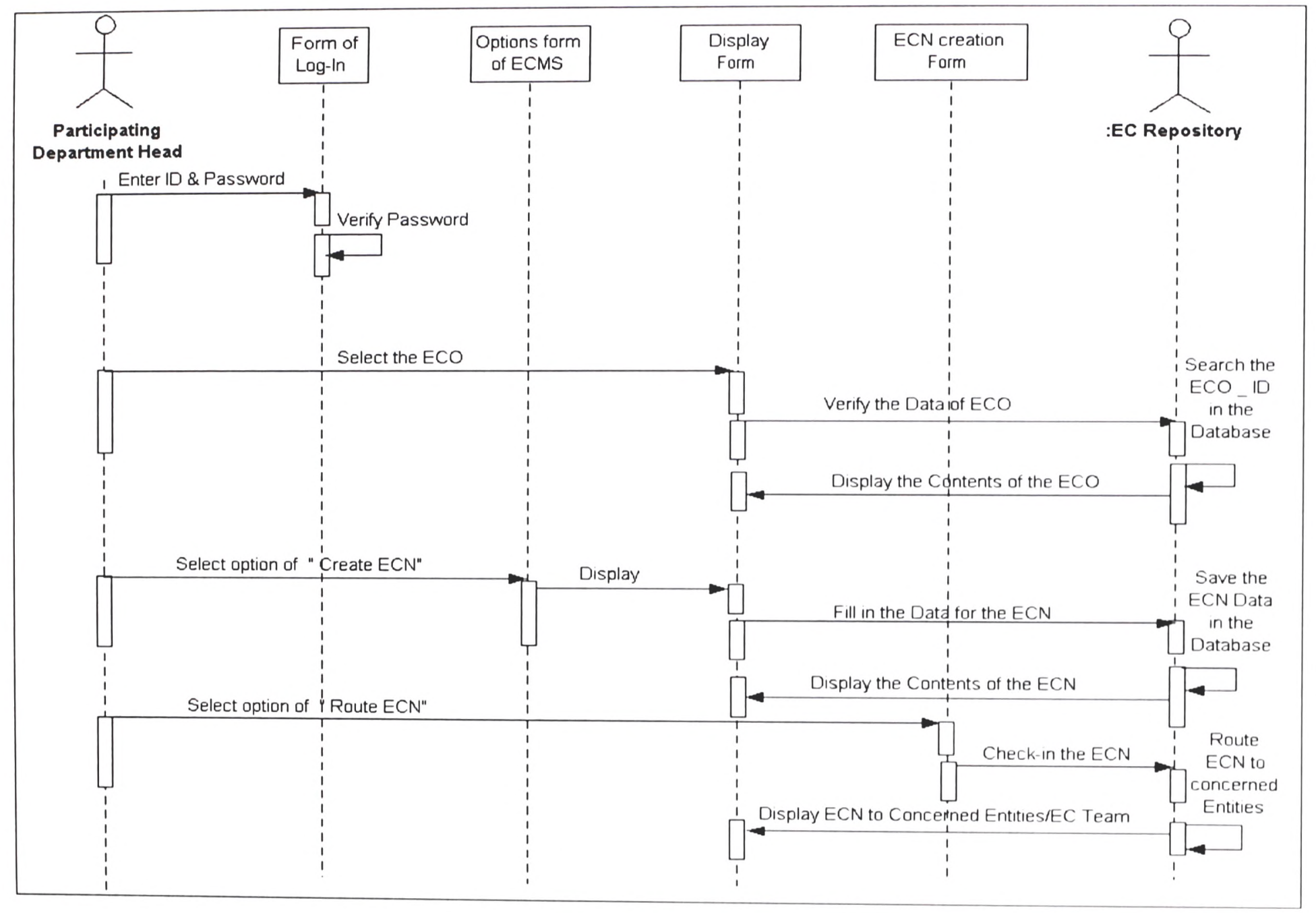




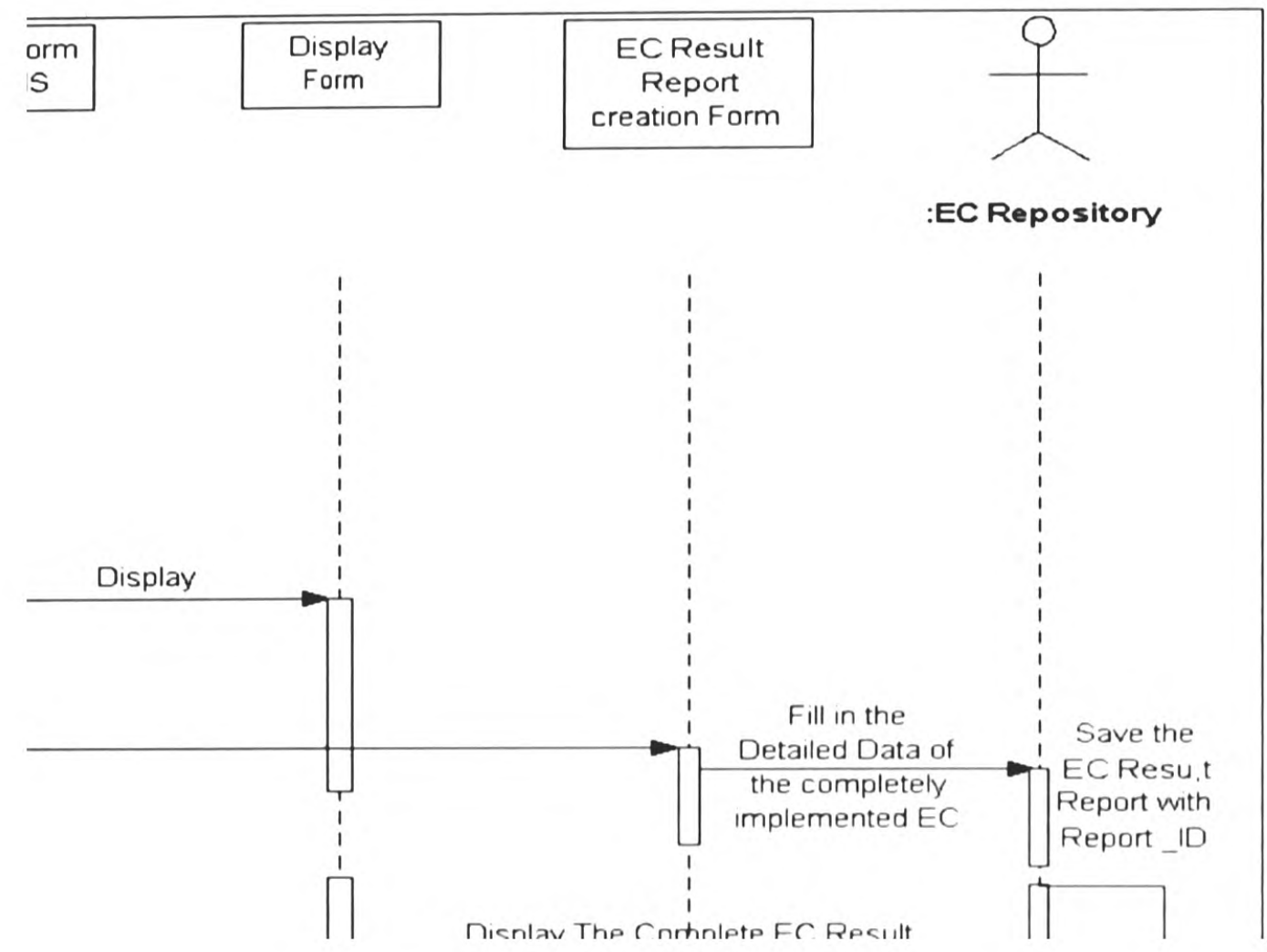

